\title{
Structure-Processing-Property Relationship of Poly(Glycolic Acid) for Drug Delivery Systems 1: Synthesis and Catalysis
}

\author{
Vineet Singh and Meena Tiwari \\ Polymer Laboratory, Department of Pharmacy, Shri. Govind Ram Seksaria Institute of Technology \& Science, \\ 23-Park Road, Indore 452003, India \\ Correspondence should be addressed to Meena Tiwari, mtiwari@sgsits.ac.in
}

Received 1 July 2010; Accepted 25 September 2010

Academic Editor: Peng He

Copyright ( $) 2010$ V. Singh and M. Tiwari. This is an open access article distributed under the Creative Commons Attribution License, which permits unrestricted use, distribution, and reproduction in any medium, provided the original work is properly cited.

Till date, market is augmented with a huge number of improved drug delivery systems. The success in this area is basically due to biodegradable polymers. Although conventional systems of drug delivery utilizing the natural and semisynthetic polymers so long but synthetic polymer gains success in the controlled drug delivery area due to better degradation profile and controlled network and functionality. The polyesters are the most studied class group due the susceptible ester linkage in their backbone. The Poly(glycolic Acid) (PGA), Poly(lactic acid) (PLA), and Polylactide-co-glycolide (PLGA) are the best profiled polyesters and are most widely used in marketed products. These polymers, however, still are having drawbacks which failed them to be used in platform technologies like matrix systems, microspheres, and nanospheres in some cases. The common problems arose with these polymers are entrapment inefficiency, inability to degrade and release drugs with required profile, and drug instability in the microenvironment of the polymers. These problems are forcing us to develop new polymers with improved physicochemical properties. The present review gave us an insight in the various structural elements of Poly(glycolic acid), polyester, with in depth study. The first part of the review focuses on the result of studies related to synthetic methodologies and catalysts being utilized to synthesize the polyesters. However the author will also focus on the effect of processing methodologies but due some constraints those are not included in the preview of this part of review.

\section{Introduction}

Biodegradable polymers can be efficiently utilized for various purposes such as drug delivery, orthopaedic, dental, and tissue engineering [1-7]. Such sophisticated applications usually require polymers with narrowly defined material properties. For a polymer to be used in drug delivery system, it is desired that it should degrade in prerequisite manner [8-12]. The rate of degradation (Hydrolytic and proteolytic degradation) of any polymer chiefly depends on its primary structure properties (Backbone and functionality characteristics), and secondary structural properties such as morphology, mechanical properties (tensile strength and modulus), the thermal properties (glass transition temperature $T_{g}$, softening or melting point, degradation temperature) and the viscoelastic properties (storage and Loss moduli and $\tan \delta$ ). The quality of these physicochemical properties depends on the structural features, such as backbone characteristics, functionalities, and crystal packing structure, of the polymers [13-28].

Degradable aliphatic polyesters (bearing ester linkage $\left.-\mathrm{CH}_{2}-\mathrm{COO}-\right)$ are having special significance in drug delivery systems as the ester bonds can be cleaved under physiological conditions ( $\mathrm{pH}$ 7.4) in absence of proteolytic activity [29]. Among the polyesters, the polymers derived from $\alpha$-hydroxy acids (PHA) have found the most extensive use.

Poly ( $\alpha$-hydroxy acids) such as poly (glycolic acid) (PGA) and poly(lactic acid) (PLLA) having excellent mechanical properties and biological affinity are the most widely studied 
polymers. However, their crystallinity, hydrophobic nature and lack of functional diversity in the backbone have interfered with modulation of their degradation rate, mechanical properties and morphology.

The mechanical properties, morphology and rate of degradation of a polymer can be balanced and controlled by an appropriate choice of primary structural elements such as monomer stereochemistry, co-monomer ratio, polymer chain linearity, polymer molecular weight and processing parameters such as annealing time and temperature. All these requirements can only be attained when one would be able to define the primary structure in terms of these elements and their quantitative effect on the requisite physicochemical properties. A number of qualitative and quantitative models describing the various phenomenons have been developed by the scientists [30, 31].

The present report is to draw the attention of the researcher's towards an area of relevant success describing the various models developed for defining the structural organisation of Poly(glycolic acid) and correlating them with its physicochemical properties.

\section{Poly(Glycolic Acid) (PGA)}

PGA is biocompatible and has been known since 1954 to be a potentially low-cost tough fibre forming polymer. In 1962, PGA was developed as the first synthetic absorbable suture, Dexon, by American Cyanamide Co. DuPont considered the polymer of the homologous $\alpha$-hydroxy acids, poly(lactic acid) (PLA), for the same application [32-35].

PGA is the simplest aliphatic polyester of the type $-\left[-\left(\mathrm{CH}_{2}\right)_{z}-\mathrm{CO}-\mathrm{O}-\right]_{n}-$; it has a glass transition temperature between $35-40^{\circ}$ and melting point ranging from 224$227^{\circ} \mathrm{C}$. Because of its simple chemical structure and stereoregularity, it occurs with different degree of crystallinity from completely amorphous to a maximum of $52 \%$ crystallinity. Chatani and co-workers determined the crystal structure of PGA by X-ray diffraction (Figure 1). Two macromolecular chains pass through the orthorhombic unit cell of dimensions $a=5.22 \AA, b=6.19 \AA$, and $c$ (the fibre axis) $=7.02 \AA$ (Figures 2 and 3 ). The planar zig-zag chain molecules form a sheet structure parallel to the ac plane and do not have the polyethylene type arrangement. High density of the crystalline, $1.69 \mathrm{~g} / \mathrm{cm}^{3}$, namely the tight molecular packing and the close approach of the ester groups might stabilize the crystal lattice and contributes to the high melting point of this polymer [36-43].

The crystallinity of PGA in Dexon Suture is typically in the range of $46-52 \%$ and it tend to lose mechanical strength rapidly, typically over a period of 2-4 weaks after implantation [44-54]. Sato et al. [55] prepared the microspheres, encapsulating methylene blue and prednisolone acetate, using three methods freeze dried, Solvent evaporation, solvent extraction precipitation methods and with different percentage of loading concentration of marker. In all the three methods, uniform, spherical microspheres formed but with different degree of porosity. In their study they have noticed an initial burst release followed by a zero-ordered release. Redmon et al. [56] prepared

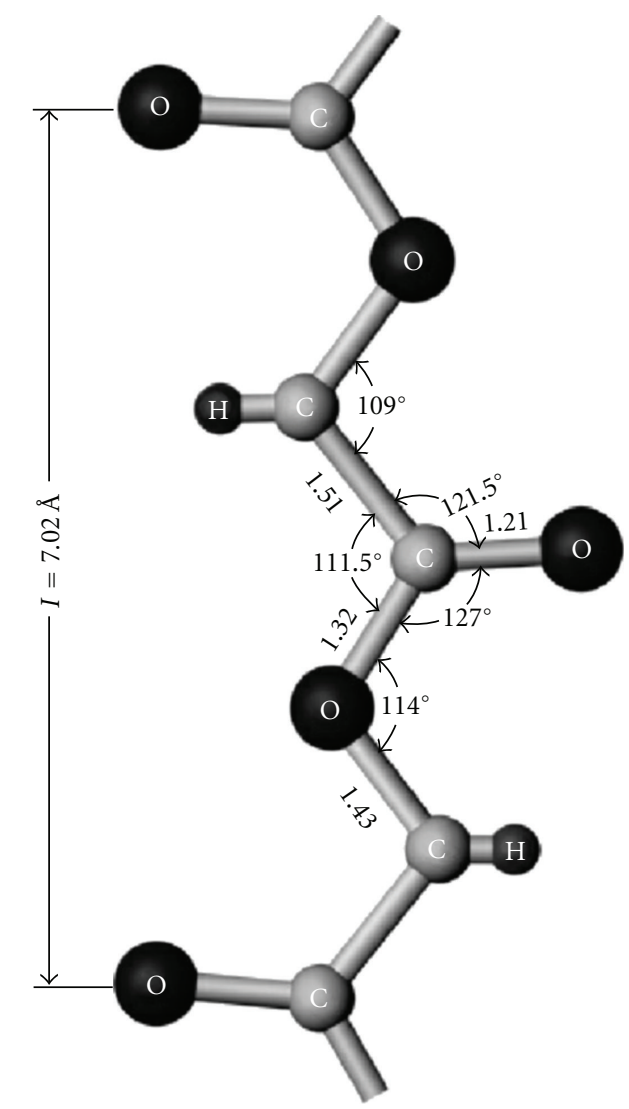

FIGURe 1: Molecular dimensions of poly(glycolic acid).

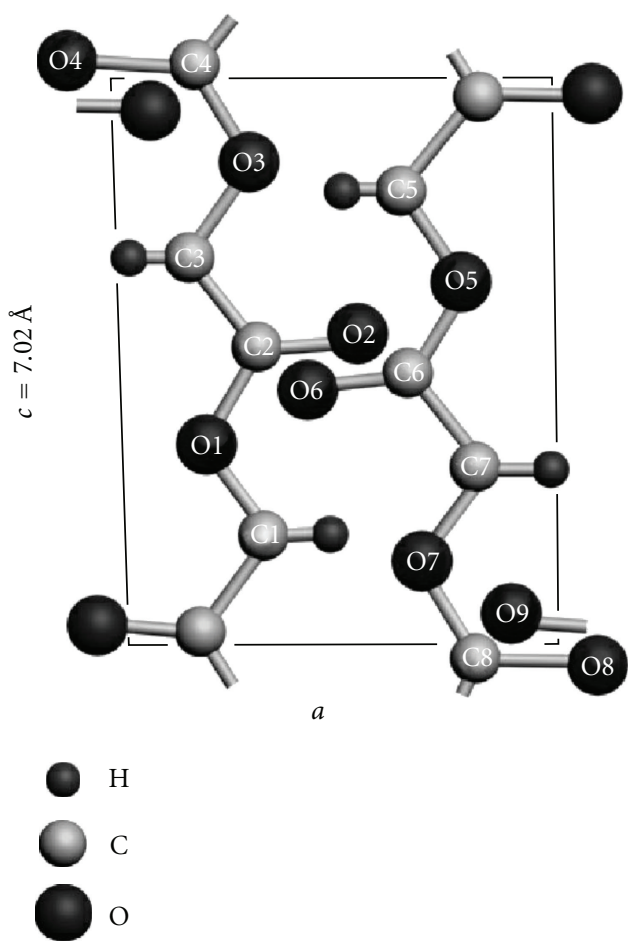

FIGURE 2: Crystal structure of poly(glycolic acid). 


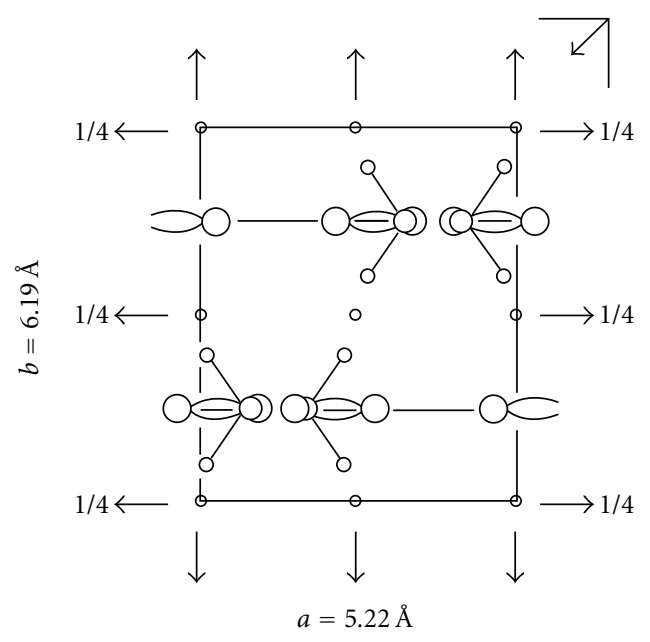

(a)

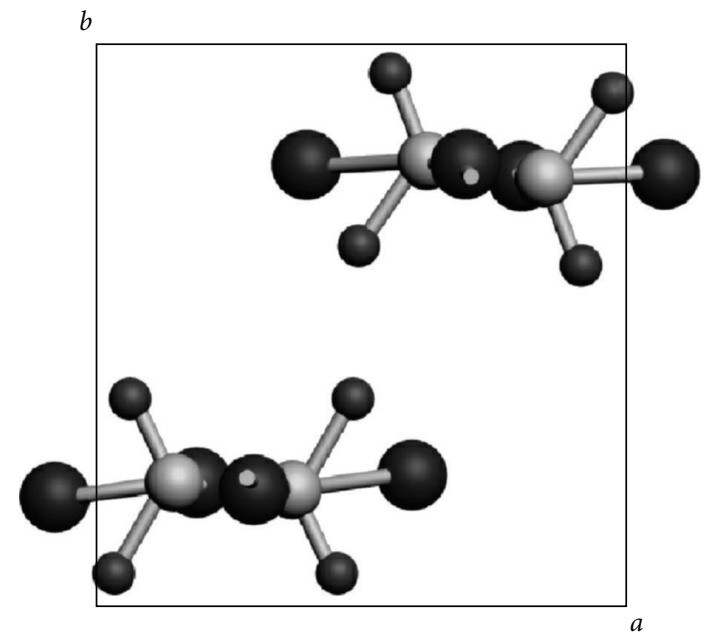

(b)

FIGURE 3: Crystal structure of poly(glycolic acid).

the prednisolone-21-acetate poly(glycolic acid) microspheres using solvent-evaporation as well as freeze drying method. Although the morphology of the microspheres prepared by two methods were different smooth round surfaced with solvent evaporation and somewhat more irregular with freeze dried but both the kinds have somewhat similar drug release profile having rapid initial (86-89\% in solventevaporation-precipitation, $69-70 \%$ in freeze drying,during initial 8 hours), followed by a more gradual release of the remaining drug over the next 64 hours $(11-14 \%$ in solventevaporation-precipitation, $30-31 \%$ in freeze drying, resp.). Similarly, Hazrati et al. [57] prepared the microspheres of indium -111 labeled poly(glycolic acid) by solventevaporation-precipitation and studied the tissue distribution of microspheres. They were able to get peak activity in the liver with-in 8 hours, suggesting an initial burst release followed by a gradual release in-vivo too.

\section{PGA Synthesis and Molecular Weight}

Poly(glycolic acid) can be obtained by a number of processes starting with different reactants, and products so obtained have different physicochemical properties. Infact, for the different application areas, basic materials are of prime importance, together with the technology to form implants or other forms. For instance, in the orthopaedic field, mechanical properties and design (which of course are closely related) of the end product will be essential; to a lesser extent this will be the case in the pharmaceutical field, and so less attention needs to be paid to these aspects. Jigang et al. [58] established a commercial method for synthesis of poly(glycolic acid) using a stirred reactor. They had reported a study correlating the change in intrinsic viscosity, monomer conversion rate and thermal stability of polymer during the process of polymerization.

The following methods and technologies are used to prepare poly(glycolic acid).

\subsection{Low Molecular Weight PGA Synthesis}

3.1.1. Direct Polycondensation Polymerization of Synthetic Glycolic Acid [59-67]. Polycondensation of glycolic acid is the simplest process available to prepare PGA, but it is not the most efficient one because it yields a low molecular weight product. Briefly, the procedure is as follows: glycolic acid is heated at atmospheric pressure and a temperature of about $175-185^{\circ} \mathrm{C}$ is maintained until water ceases to distill. Subsequently, pressure is reduced to $150 \mathrm{~mm} \mathrm{Hg}$, still keeping the temperature unaltered for about two hours and the low molecular weight poly (glycolic acid) is obtained. The polymer obtained has a low molecular weight, because it is hard to remove water completely from the highly viscous reaction mixture; therefore a polymer of a molecular weight of a few ten thousands is obtained. In the polycondensation system of PGA, two principal equilibrium exist, one is dehydration equilibrium for esterification Scheme 1 and the other is ring chain equilibrium involving depolymerization to glycolide Scheme 2 [68].

Even the reaction is conditioned at high temperature and high vacuum for dehydration, but also the formation of glycolide in equilibrium with PGA. The polymer, thus, possesses inferior mechanical properties but quite perspective for drug delivery purposes due to high amorphousity required for uniformity in formulation and biocompatibility [69]. For the purpose of drug delivery, Zhaoyang et al. [70] reported the synthesis of poly(glycolic acid) by direct melt polymerization. In their work, they had synthesized poly(glycolic acid) by direct melt polymerization at $165^{\circ} \mathrm{C}$ and $70 \mathrm{~Pa}$ for 10 hours with tin bichloride as catalyst and characterized by IR, DSC and X-ray diffractometry. The poly(glycolic acid) obtained by this method had higher crystallinity and crystallite size. Enomoto et al. [71] reported a direct method for synthesis of poly(L-lactic-acid) by melt polycondensation under continuous microwave radiation. 


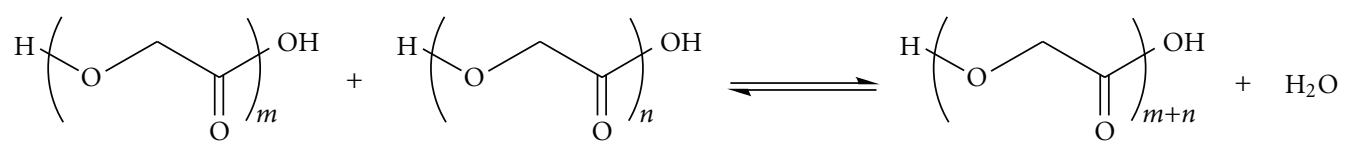

Scheme 1: Polycondensation-dehydration equilibrium for esterification.

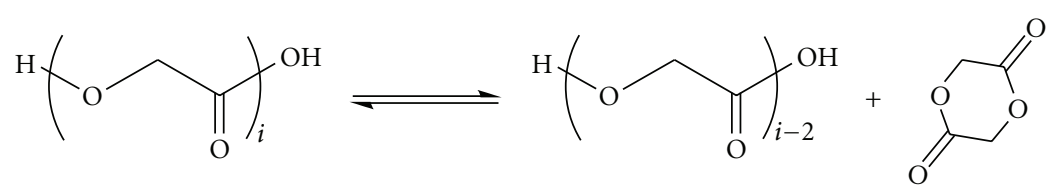

Scheme 2: Polycondensation—ring chain equilibrium involving depolymerization to glycolide.

3.2. High Molecular Weight PGA Synthesis. A number of process and technologies have been developed for synthesis of high molecular weight PGA.

3.2.1. Azeotropic Condensation Polymerization of Glycolic Acid. High molecular weight PGA can also be synthesised azeotropically [72-77]. In this approach, the problem of the removal of water is overcome by manipulating the equilibrium between a monomer and a polymer in an organic solvent and thus glycolic acid is polycondensed directly into a polymer of a high molar mass. It is a solution polymerisation technique, using a high activity catalyst and a low boiling organic solvent. Water as a by-product is removed azeotropically, whereas solvent is dried and recycled back in the reaction. This polymerisation technique allows a reaction temperature to be chosen below the melting point of polymer, and thus efficiently prevents depolymerization and racemization during polymerisation.

3.2.2. Ring-Opening Polymerization of Glycolide, a Cyclic Dimer of Glycolic Acid. The earliest attempt to prepare polyhydroxy acid using ring opening polymerization was reported by Carothers for poly(lactic acid) in 1932 [78]. However they were able to get only the low molecular weight polymer. It was in 1950s that we were able to obtain high molecular weight polylactones using ring opening polymerization techniques due to efficient monomer purification techniques. The generalised scheme for the preparation of PGA can be represented as Scheme 3.

Leenslag and Pennings [79] studied the synthesis of homopoly(glycolic acid) from glycolide by the ring opening polymerization using different catalysts. They also evaluated the effect of purity of monomer, catalyst concentration and polymerization time on the polymer molecular weight.

The process of ring opening polymerization of glycolide can be any of the following type with the difference in the quality of the end product.

(a) Melt and/or Bulk Polymerization of Glycolide [8092]. In this, first the $\alpha$-hydroxy acid is dehydrated to give a low molecular weight polymer. In the second step the low molecular weight polymer is heated under a high vacuum and in presence of a suitable catalyst to give the crude monomers. This process is usually referred to as ring closure.
Several purification steps (crystallization/distillation) are used to give high purity monomers for use in polymerisation. One of the most important criteria regarding the monomers is their free acid content. Essential to the whole process is that the monomers do not contain water and are not able to generate water as a reaction product during reaction to high molecular weight compounds.

With bulk polymerization, the reaction temperature is between the melting temperatures of the monomers used and the melting or softening point of the resulting polymer. Usually this type of polymerization is carried out at temperatures slightly above the melting point of the monomers, resulting in a solidification of the bulk of the material at an early stage of the reaction. In the case of the above mentioned production of basic materials for suture production, a much higher temperature is used, enabling the reaction mass always to be, in general, in a highly viscous form. After a certain period of time, the temperature of the reacting mixture is raised to a temperature higher than the melting temperature of the resulting polymer: in this case the bulk-polymerization has become a melt-polymerization. In general, melt-polymerization is conducted at temperatures higher than the melting point or softening point of the resulting polymer.

Bulk polymerisation has the advantage that very high molecular weights can be obtained, provided that the temperatures of polymerization and reaction conditions are well chosen. There are more advantages with this polymerization form, one of which is the fact that less degradation products are produced during polymerization. A disadvantage is the end form in which the polymer is produced. Because the polymer crystallizes/solidifies during the reaction, the resulting polymer always takes the shape of the reactor in which it is produced. Leenslag and co-workers found that bulk polymerizations performed at fairly low temperatures produced high molecular weight poly(L-lactic acid) with a highly porous texture, giving the material special mechanical properties, such as improved impact strength, indicating favourable applications in the orthopaedic field. It was reported by the same group that there was a relationship between polymerization temperature, heat of fusion (indicative of the crystallinity of the material), molecular weight and yield of polymerization. Among the conclusions was one concerning the ceiling temperature, the temperature above 


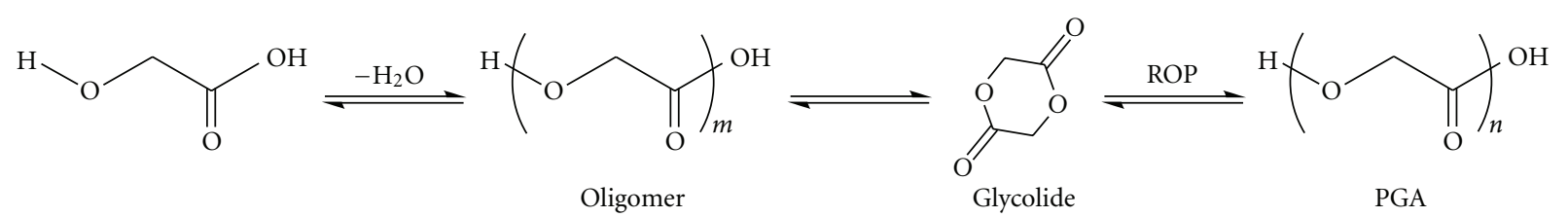

Scheme 3: General scheme of ring opening polymerization.

which no polymerization will occur or, in other words, no polymer will be formed. This temperature should be about $270^{\circ} \mathrm{C}$. With the applied conditions it seemed unlikely that poly(lactic acid)could be synthesized at temperatures higher than $270^{\circ} \mathrm{C}$.

Yingting et al. [93] studied the effect of catalyst types, reaction temperature, the gradient temperature and process control on the synthesis of the poly(lactic acid) via melt polycondensation by using lactic acid as raw material. They concluded that the gradient temperature and pressure control could greatly improve the molecular weight and yield of PLA, and optimum condition was that the content of $\mathrm{SnCl}_{2}$ and p-toluenesulfonic acid catalyst was $0.5 \%$ based on the amount of lactic acid monomers, and the reaction was carried out firstly at $1000 \mathrm{~Pa}$ and $120^{\circ} \mathrm{C}$ for 4 hours and then at $500 \mathrm{~Pa}$ and $180^{\circ} \mathrm{C}$ for 8 hours. The molecular weight of obtained PLA was $151000 \mathrm{~g} / \mathrm{mol}$ and the yield was up to $82.12 \%$.

Degradation studies performed by Leiper and co-workers agree fairly well with this conclusion; above temperatures of $270-300^{\circ} \mathrm{C}$. PGA, PLA and their copolymers degrade to several degradation products, among which are carbon dioxide, the monomers and formaldehyde (in the case of PLA-acetaldehyde).

The polymerization of the monomers is an exothermic reaction: during the reaction heat is evolved from the reaction mixture. Because of the very poor heat transfer that is generally exhibited by plastic or polymers, this causes a severe problem, even on the aforementioned small-scale. Heat generation in a certain period of time is, of course, strongly dependent upon polymerization temperature and choice of initiator and co-reagents. In a reactor, at the walls the temperature will be nearly same as the temperature of the surroundings, for instance an oil bath maintained at $105-140^{\circ} \mathrm{C}$. Going from outside wall to the inside of the reacting mixture, the temperature will rise due to heat generation during reaction: this heat cannot be removed due to poor heat transfer. Under normal conditions the temperature increase can be as high as $40-80^{\circ} \mathrm{C}$. The result of this temperature difference within the batch represented in the same figure. In accordance with the depicted relationship between molecular weight and temperature reported by Leenslag \& Pennings [79] a molecular weight decrease from the outside to the inside will be presented. Even in medium sized batches of a few hundred grams of material at normal reaction conditions, the polymers can exhibit brown interior and fully white exteriors. This phenomenon is scattered in the case of polymers which are highly crystalline. The browning of the interior is due to degradation of polymer and side reactions. In the case of the polymerization of glycolide these effects are even more profound for several reasons.

In the patent literature it is stated that, in case of the use of stannous octoate catalyst, the catalyst is fully compatible/soluble with the molten monomer; this is only partly true. It was found that the catalyst is only soluble in the molten glycolide monomer for temperatures from about $125-135^{\circ} \mathrm{C}$ [94]. This means that polymerization of this monomer at temperatures frequently reported for the polymerization of lactides, $105 / 125^{\circ} \mathrm{C}$, cannot be used in this case. Homopolymers of glycolide can only be made with the use of the aforementioned initiator from temperatures of about $130^{\circ} \mathrm{C}$, indicating that the reaction rate is higher than in lactide polymerization performed at lower polymerization temperatures. Together with the fact that glycolide reactions are more exothermic than the corresponding lactide reactions, the conclusion can be made that the glycolide reactions are more difficult to perform [95-98]. For instance, even at batch sizes of 20-30 grams, the normal polymer glycolides produced have interiors with many exotic colours, stemming from degradation products.

The purity of the monomers is of importance for the end result of the polymerization. The effect of free acid content has a deleterious effect in attaining high molecular weight of the resulting polymer $[99,100]$. Mixing of the monomers with free acids thus provides a tool for the control of the reaction. From industrial point of view these phenomena, together with the reactor form the polymer is produced in, require special design, reaction conditions and consequently, downstream processing of the resulting materials.

Melt polymerization differs from the bulk polymerization, in that the polymerization is conducted at temperatures higher than the melting point or softening point of the resulting polymer. The polymerization resulted in polymers of medium molecular weight. The following procedure describes this method of polymerization. A reactor is filled with the monomer, initiator and co-reagents, after which the temperature is raised to far above the melting point of the monomer or monomer mixture. The first stage is usually a type of bulk polymerization, meaning that the temperature of polymerization is below the melting temperature of the resulting end product or below the softening point of the resulting polymer (in the case of highly amorphous polymers). In general, the viscosity of the polymerization mixture is very high, but it is still possible to stir the reaction mixture. When the viscosity of the reaction mixture becomes too high, the temperature is raised to a polymerization temperature higher than that of the resulting polymers, thus rendering the field of melt polymerization. 
For small-scale production, raising the temperature is not always necessary: the polymerizations are fully performed as a type of bulk-polymerization. This is only possible on a small-scale because of the poor heat transfer. During reaction the polymer mixture solidifies or crystallizes. Of course, stirring is not possible any more when this stage is reached. On a larger scale, temperatures have to become higher to enable stirring of the reaction mixture, thus enabling a good heat transfer. In general, temperatures ranging from $140-230^{\circ} \mathrm{C}$ are used during this type of polymerization.

The resulting polymers are, in general, light yellowish to deeper brown polymers which can be used for the production of fibres. The yellowish or darker colours stem from degradation products which are produced during the reaction. The intrinsic viscosities (IVs) of the resulting polymers range from 1 to 2.5 enabling the polymers to be used in common spinning and processing.

The reason for the low/medium molecular weights that are produced stems from two processes. One is that at higher temperatures the reaction tends to go to lower molecular weight polymers: at a high enough temperature, no polymerisation occurs due to degradation reactions. The other reason is that co-reagents are introduced to the reaction mixture which slow down the reaction and/or lower the resulting molecular weight.

For instance, when melt polymerization is performed with use of stannous octoate catalyst, depolymerisation occurs at any stage of the reaction, and is an equilibrium reaction. At higher temperatures, the equilibrium tends to go towards the side of the monomers. It is known from patent literature that in these cases, and with temperatures up to $180^{\circ} \mathrm{C}, 5-10 \mathrm{wt} \%$ monomers can be present in the resulting polymer.

(b) Solution Polymerization of Glycolide [101, 102]. The advantages of bulk-polymerization are the high molecular weights that can be produced without severe degradation products; the disadvantage is the heat generation during synthesis and consequently the problems that come with large scale synthesis. The advantages of melt polymerization are the simple procedures; the disadvantages are the limited range of molecular weights that can be produced and the presence of degradation products in the resulting polymer.

The solution polymerization could prevent part of the problems that are encountered with the aforementioned types of polymerization. Essential in solution polymerisation is the relatively low monomer concentration compared to the bulk and melt-polymerization. Consequently, low viscosities and thus better heat transfer due to the possibility of mixing during reaction, are present and the problems due to the exothermic reactions are prevented. Because of the better controlled synthesis, the reproducibility of the reaction is better, another important criterion to consider in polymerization. Another aspect of this type of polymerization is that large batches can be easily made. Of course, as with the other polymerization procedures, disadvantages are there too. For instance, it involves the use of solvents which have to be removed from the polymer at a later stage.
Solution polymerization can have advantages if certain polymers are required. In particular, crystalline polymers of fairly high molecular weights can be made by this method. It was found that molecular weights up to two times the molecular weights that are usually produced with the meltpolymerization could be obtained. Besides the high molecular weights, the reproducibility of the polymerizations was in good agreement. Another advantage was the downstream processing of the material; after polymerization is completed it is very easy to purify and dry the material. The yield of the resulting materials ranging from $96-100 \%$ can be obtained with the use of solution polymerization. After completion of the polymerization reaction, the polymer solution is cooled down and the polymer crystallizes from the reaction mixture. Separation of the polymer from the solvent is done by common methods, as well as the purification and drying of the polymer. The fact that crystallization is used gives one of the drawbacks of the system; only polymers that are able to crystallize from common solvents can be used with this method. It is difficult to make copolymers with this method without the use of other solvents or nonsolvents.

The drawback of solution polymerization can be indicated from the results obtained is that during solution polymerization, racemization occurs.

(c) Suspension or Emulsion Polymerization of Glycolide. This polymerization technique is usually a process in which a water-insoluble monomer is dispersed or suspended in water to give small droplets of the suspended monomer. Droplet sizes may vary from tenths of a micron to hundreds of microns. Usually, the suspension is stabilized by mechanical stirring and with the addition of a stabilizer, a macromolecular substance such as polyvinyl alcohol. The stabilizer protects the formed droplet by creating a very thin layer of molecules around the droplet. During polymerization it prevents the individual droplets from forming aggregates. Aggregates can be formed during polymerization because of the increasing viscosity: at a certain stage the polymer becomes sticky and aggregation will occur. The process is initiated/catalysed by monomer-soluble catalysts and initiators. This means that the system can be considered as a series of bulk polymerizations, where polymerization takes place at the same time and under the same reaction conditions. Because nothing happens in the continuous phase, the viscosity in the whole system is constant. Again, the low viscosity during polymerization enables a very good heat transfer.

British Patents 825.335 and 932.382 describe a type of suspension polymerization of glycolide and lactide in a nonwater system. In a series of experiments different gasolines were used, which have, of course, a negative aspect: their highly explosive character. The polymerization system was stabilized by silicon-oil. However, the results were not that good in that low molecular weight polymers were synthesized. But in another experiments done by Jan et al., they used suspension polymerization using some nonsolvent systems. They used gasoil-L-lactide-stannous octoate system. Initially the reaction started at normal reaction condition and then the temperature ranged from $80-160^{\circ} \mathrm{C}$ from few hours to 20-30 hours were used. After the reaction 
was completed the system was allowed to cool to room temperature, after which the polymer was separated from the nonsolvent. The resulting polymers were quite easy to process and dry and molecular weight up to 175000 were obtained. The final material formed was in globular forms as expected with very porosity. This high porosity is caused by the crystallization of the formed polymer during the reaction.

Recently, Cui-qiong et al. [103] synthesized poly(glycolic acid) with a relatively high molecular weight and an inherent viscosity of 0.9 was prepared by means of suspension polymerization using methyl silicone oil as disperse medium.

\subsubsection{Oligomerization of Glycolic Acid and Chain Coupling} Reaction. The molecular weight of the oligolactone can be increased utilising chain coupling agents. These coupling agents preferentially react with hydroxyl or carboxyl group, which leads to different reaction rate of coupling (Scheme 13).

Various esterification-promoting adjuvants and chainextending agents have been reported by Buchholz that can be used to increase the molecular weight of the lactones condensation products. Some examples of the esterification promoting adjuvants are bis(trichloromethyl) carbonate, dicyclohexylcarbodiimide, and carbonyl diimidazole. These adjuvants produce reaction byproducts that must be either neutralized or removed. Bis(trichloromethyl) carbonate creates hydrochloric acid, which can degrade the polymer, or dicyclohexylcarbodiimide forms unreactive and insoluble dicyclohexylurea, which can be filtered out during the final purification steps. The advantages of esterificationpromoting adjuvants are that the final product is highly purified-free from residual metals, catalyst, and lowmolecular-weight oligomers. The disadvantages are higher costs due to the increased number of reaction steps, the use of dangerous or flammable solvents, inability to form copolymers containing different functional groups, and the additional purification and separation steps of nonrecoverable byproducts [104-119]. The use of chainextending agents overcomes many of the disadvantages associated with esterification-promoting adjuvents. Reactions involving chain-extending agents are more economically feasible, as they can be done in the melt with lower amounts of chain-extending agents required and separate chain-extending steps arenot needed. Improved mechanical properties associated with the chain-extending agent are also found, and the flexibility to manufacture copolymers with different functional groups is greatly expanded. The disadvantages are that the final polymer may still contain unreacted chain-extending agents, residual metal, or polymer impurities, or the extending agents are not biodegradable or bioabsorbable. Some examples of chain-extending agents are isocyanates, acid chlorides, anhydrides, epoxides, thiirane, and oxazoline. The disadvantages of using isocyanates as chain extenders are the toxicity and sensitivity effects associated with the isocyanate monomers and their subsequent toxic amine hydrolysis products.
3.2.4. Reaction of Bromo or Chloroacetic Acid with Triethylamine in a Nitromethane Solution. Pinkus and Subramanyam [120] reported a new, one step synthesis of poly(glycolic acid). According to their method, triethylammonium bromoacetate was prepared by reacting triethylamine with bromoacetic acid in chloroform solution. On standing, a poly(glycolic acid) precipitate formed in the solution and a chloroform-soluble product was identified as triethylammonium bromide. The structure of poly(glycolic acid) so formed was characterized using hydrolysis, ${ }^{1} \mathrm{H}$ NMR, IR spectra, and X-ray powder diffraction, which indicated partial crystallinity. A lower limiting value of the number-average molecular weight of $10^{4}$ was determined by cryoscopy. Similarly, Yuxiang et al. [121] reported one step synthesis of poly(glycolic acid) from chlorocetic acid. In their work, they have reported the effect of the mole ratio of chloroacetic acid to triethylamine, polymerization time, solvent and washing agent on the product and found that optimum mole ratio of chloroacetic acid to triethylamine was $1.0-1.1: 1.0$, the reaction time was $4-5$ hours, the solvent was chloroform, and the washing agent was ethanol.

\subsubsection{Acid-Catalyzed Reaction of Carbon Monoxide and} Formaldehyde. According to Masuda et al. [122] PGA can also be obtained by reacting carbon monoxide, formaldehyde or one of its related compounds like paraformaldehyde or trioxane, in presence of an acidic catalyst. In a carbon monoxide atmosphere an autoclave is loaded with the catalyst (chlorosulfonic acid), dichloromethane and trioxane, then it is charged with carbon monoxide until a specific pressure is reached; the reaction is stirred and allowed to proceed at a temperature of about $180^{\circ} \mathrm{C}$ for two hours. Upon completion the unreacted carbon monoxide is discharged and a mixture of low and high molecular weight poly(glycolic acid) is collected.

3.2.6. Enzyme-Catalyzed Reactions. A vast number of enzymes catalyze metabolic reactions via biosynthetic pathways in living cells. The need to develop environment friendly processes and products has culminated in alternative routes for the generation of synthetic polymers and in vitro enzyme catalysts is one of the most promising options. The use of enzymes for in vitro polymer synthesis has been actively pursued in the last decade. Enzymatic polymerization is an in vitro polymerization via nonbiosynthetic pathways catalyzed by an isolated enzyme. Lipase catalysed polymerization is an ecofriendly technique for the preparation of useful polyesters by polycondensation as well as ring opening polymerization reactions.

An early investigation in this area was done by Kobayashi and Uyama [123, 124] and Knani et al. [125] for the enzymecatalyzed polymerization of $\epsilon$-caprolactone $(\epsilon-\mathrm{CL})$ and $\delta$ valerolactone $(\delta$-VL) using Lipases form P. Fluorescens, candida cylindracea and porcine pancreatic lipase (PPL). The bulk polymerization was carried out for 10 days; with highest monomer conversion of about $92 \%$ was obtained using Lipase from $P$. Fluorescens, yielded average molecular weight (Mn) up to 7700 for $\epsilon$-CL. The polymer thus obtained was 
having both carboxyl and hydroxyl end groups. MacDonald et al. used PPL as catalyst and butanol as initiator for solution polymerization of $\epsilon$-CL using dioxane, toluene and heptanes as solvents and synthesised low molecular weight polymer with $\mathrm{Mn}=2700$ [126]. Up till now, unsubstituted lactones with ring size from 4 to 17 have been polymerized using lipases from Aspergillus niger (lipase A), Candida antartica (lipase B, Novozyme 435), Candida rugosa (lipase AYS), Mucor javancius (lipase M), Mucor methei (lipozyme), porcine pancreatic lipase (PPL), Pseudomonas aeruginosa (lipase PA), Pseudomonas cepacia (lipase PS), Pseudomonas fluorescenes (Lipase PF), Pseudomonas sp. Lipase (PSL), Rhizopus delmer (lipase RD), and Rhizopus japonicas (lipase RJ) and so forth. The preferred lipase system used is generally a physically immobilised form of Candida antartica known as Novozyme-435.

Nobes et al. [127] was first to report Lipase-catalyzed polymerization of four-membered lactone, that is, $\beta$ butyrolactone. The polymerization was carried out for several weeks by using equal weights of lactone and lipase. Only low molecular weight polymers (molecular weight ranging from 256 to 1045 ) corresponding to chain lengths of 3-12 could be obtained. Matsumara and co-workers [128] obtained molecular weights up to 7300 by using PPL or Candida cylindracea lipase. The polymerization was carried between 60 to $100^{\circ} \mathrm{C}$ for a duration ranging from 12 to 120 hours. A significant amount of cyclic oligomers were formed during this polymerization due to intramolecular cyclization [128, 129].

Using PPL or Pseudomonas cepacia unstrained $\gamma$ butyrolactone was polymerized and yielded polymers with 10-11 repeat units [127]. This is interesting information because this monomer is stable and does not polymerize by using a chemical route (aluminoxane initiators). Lipase also catalysed the polymerization of relatively unstrained sixmembered $\delta$-Valerolactone. The ring strain energies in four membered lactones as $\beta$-butyrolactone \& $\beta$-propiolactone have been estimated to be around $33 \mathrm{kcal} / \mathrm{mol}$ [127] and for five-membered $\gamma$-butyrolactone as $8.8 \mathrm{kcal} / \mathrm{mol}$ whereas seven-membered lactone $\epsilon$-CL around $10.7 \mathrm{kcal} / \mathrm{mol}$. In the lipase catalysed polymerization of lactones, the rate of polymerization as well as degree of polymerization is independent of ring strain.

Till date the experiments done using enzymes for in vitro polymerization reaction yielded low molecular weight range polymer. Although a number of investigations are going to overcome these inadequacies by changing reaction parameters (i.e., Solvent, temperature, enzyme concentration etc.). Matsumara et al. [130] reported the lipase PC catalysed polymerization of cyclic diester D,L-lactide at a temperature of $80-130^{\circ} \mathrm{C}$ to yield poly(lactic acid) with molecular weight greater than $10^{4}$. A high molecular weight polymer was also obtained by lipase CR-catalyzed polymerization of $\beta$ propiolactone [131].

The lipase-catalyzed polymerization of lactones is believed to proceed by the activated monomer mechanism. The catalytic site of lipase is serine residue which forms a complex with the lactone leading to the formation of the acyl-enzyme intermediate (AM). This intermediate reacts with water or alcohol to regenerate the enzyme and a $\omega$ hydroxycarboxylic acid or ester according to the reaction in Scheme 14.

In the propagation step, nucleophilic attack of the terminal hydroxyl group of the propagating polymer on the acyl-enzyme intermediate leads to the addition of one more unit to the chain and regeneration of the enzyme.

Enzymatic polymerization of 1,4-dioxane-2-one was carried out at $60^{\circ} \mathrm{C}$ for 15 hours by using $5 \%$ wt of immobilized enzyme lipase CA [132]. An increase in the amount of water up to $100 \mathrm{ppm}$ increased the rate of polymerization, but excess water $>224 \mathrm{ppm}$ depressed the rate. A polymer with weight average molecular weight of 41000 could be obtained.

Studies on $\epsilon$-CL polymerization using several commercially available lipases in the presence or absence of organic solvents have been reported by several workers. Some enzymes showed high catalytic activity for $\epsilon$-CL and less than $1 \mathrm{wt} \%$ of the enzyme was sufficient for polymerization, whereas in other cases, a very large amount of enzyme was needed for initiating the polymerization [129], and cyclic structures were obtained in the presence of organic solvents [133].

Lipase catalysed ring-opening polymerization of lactones with ring size of nine (8-octanolide), twelve (11undecanolide), thirteen (12-dodecanolide), sixteen (15pentadecanolide), and seventeen (16-hexadecanolide) has been reported in the literature. Macrolids have virtually no ring strain and their anionic polymerizability is much lower than that of $\epsilon$-CL. Surprisingly, these macrolids show unusual reactivity towards lipase polymerization, and a high molecular weight polymer can be obtained under mild conditions [134-137].

3.3. Catalysts and Initiators Used in Ring Opening Polymerization of Glycolides. The general issues with the polymerization are turnover frequency, turnover number, chemo-, region and stereoselectivity, control of molecular weight, molecular weight distribution, number and nature of polymer end groups (end group fidelity), the topology of the macromolecule (linear, branched, cyclic, concatenated, the presence and/or degree of crosslinking) and the functionality and sequence of monomer along the polymer chain.

Living ring opening polymerization, inherit the advantages of chain growth polymerization with provision of more precise control over the molecular weight and molecular weight distribution $[138,139]$. In terms of molecular weight control, the living ring opening polymerization of lactic acid (LA) yields a linear relationship between monomer conversion and molecular weight and Poly(lactic acid) with a narrow polydispersity (PDI, defined as the ratio between the weight average and number average molecular weights (Mw/Mn).

Similar to any other polymerization reaction the ring opening polymerization proceeds in three steps Initiation, Elongation and termination. Deviations from the linear dependence are attributed to the presence of slow initiation or side reactions such as chain transfer and termination reactions [140]. Side reactions such as intermolecular chain transfer to polymer and chain termination reactions are 
typically responsible for the broadening of molecular size distributions [141, 142]. Therefore, controlled polymerization requires catalysts that selectively activate monomers in preference to the propagating chains. The thermodynamics of ring-opening polymerization is driven by the release of the ring strain of the monomer. The selectivity of the catalyst is critical to facilitate ring opening relative to transesterification and other side reactions (chain shuffling and termination). Traditional thermal and hydrolytic ring opening polymerization reactions are poorly controlled and often induce a great amount of side reactions. Hence, efficient catalysts that accelerate the ring opening of cyclic monomers are needed for controlled ring opening polymerization.

Normally, depending upon the ionic charge of active propagating species, mechanisms for ring opening polymerization reactions is divided into cationic and anionic polymerization [138]. In general any catalytic ring opening polymerization reaction is either a monomer activated or chain end activated depending upon the primary locus in which catalyst play a role. A special case is zwitterionic polymerization, involving positively and negatively charged groups on the same chain [138]. However, well recognized metal catalysed ring opening polymerization reactions of lactones advance through a "coordination-insertion" mechanism involving coordination of the monomer to the metal of a catalyst and insertion of the monomer to the metal-oxygen bond (Scheme 4). The coordination-insertion mechanism differs from cationic and anionic mechanisms involving free ions or ion pairs, in that the charged propagating species and its counterion share a covalent bond.

One more mechanism involves enzymes as catalyst, also termed an activated-monomer mechanism, in which the enzyme reacts with the monomer and activates it toward enchainment onto the polymer chain end [143, 144].

High molecular weight polyesters have only been obtained by using anionic or coordination-insertion ring opening polymerization as they lead to "living ring opening polymerization" and thus, defined by the absence of termination and transfer reactions and a consequence of this is the possibility of control of molecular weight of the polymer by the adjustment of the relative concentrations of the monomer and initiator $[145,146]$.

3.3.1. Cationic Ring-Opening Polymerization. The cationic ring opening polymerization reaction of lactones has been achieved using alkylating agents, acylating agents, Lewis acids, and protic acids, however the quality of end product varies with the agents used. There are reports that polymers prepared using protic acid such as sulphuric acid and phosphoric, yield brittle and highly coloured polymers in high yield. While the polymers prepared using Lewis acids such as zinc chloride, ferric chloride, aluminium chloride, titanium tetrachloride, boron triflouride etherate, and antimony triflouride yield high molecular weight and high tensile strength PGA, especially antimony triflouride gave a tough and colourless almost quantitatively, whose reduced viscosity was higher than 0.7 . Boron triflouride was moderately active at low temperature of $110^{\circ} \mathrm{C}[145$, 146]. However, there is not much literature for the cationic ring-opening polymerization of glycolide but the study done on other lactones could be utilised to prepare PGA with desired physicochemical properties. The following attempts had been done to polymerize various lactones utilizing different catalyst.

In 1971 Dittrich and Schulz [147] were the first to report their unsuccessful polymerization of lactide with cationic compound. Later in 1980s screened a number of acidic compounds, among which trifluoromethane sulfonic acid (triflic acid, HOTf) and methyl triflate (MeOTf) proved to be useful initiators for the cationic ring opening polymerization reaction of various lactones including $\beta$-propiolactone $(\mathrm{PL})$, caprolactone (CL), valerolactone (VL), lactide and glycolide [148-151]. In case of lactide reactions were performed in nitrobenzene for 48 hours and at optimized $50^{\circ} \mathrm{C}$. They also proposed a two step propagation mechanism using end group analysis by ${ }^{1} \mathrm{H}$ NMR. It indicated methyl ester end groups when methyl triflate was used as the initiator and suggested that the polymerization proceeds by cleavage of the alkyl-oxygen bond rather than the acyl-oxygen bond. According to their proposal, reaction propagates through activation of the monomer by methylation with methyl triflate followed by $\mathrm{S}_{\mathrm{N}} 2$ attack of the triflate anion on the positively charged LA ring with the inversion of stereochemistry. Propagation was proposed to proceed by nucleophilic attack by LA on the activated cationic chain end with inversion, leading to net retention of the configuration (Scheme 5). However, regardless of the monomer to initiator ratio, the reported polymer viscosities were all quite similar, suggesting that the polymerization is not living under the reported optimized conditions [151].

In another report by Bourissou et al. [152], they found high yield during polymerization of LA at room temperature using a combination of the triflic acid as a catalyst and water or an alcohol (protic reagent) as an intiator and dichloromethane as solvent for reaction. However the reaction reached only $23 \%$ even after 2 hours in the absence of a protic initiator. Weaker acids such as $\mathrm{HCl} \cdot \mathrm{Et}_{2} \mathrm{O}$ or $\mathrm{CF}_{3} \mathrm{COOH}$ were reported inactive towards LA polymerization after 2 hours under the same conditions. They were able to obtain PLAs with molar mass up to $20000 \mathrm{~g} / \mathrm{mol}$ with polydispersity ranging from 1.13 to 1.48 using the HOTf catalyst/proton initiator system with quantitative incorporation of the protic initiator as confirmed by $1 \mathrm{H}$ NMR and ESI mass spectrometry. This linear relationship of the molecular weight versus monomer conversion and monomer-to-initiator ratio defines the controlled character of polymerization. Penczek proposed the mechanism for such controlled cationic ring opening polymerization called "activated cationic polymerization" Scheme 6. According to this, triflic acid cause protonation of LA, which follows nucleophilic attack by the initiating alcohol or that of the growing polymer chain. The presence of isopropyl ester chain ends from the initiating isopropyl alcohol suggest that polymerization proceeds by acyl bond cleavage, not by alkyl bond cleavage.

Similarly, Basko recently reported the copolymerization of L-LA and CL using triflic acid catalyst/protic initiator 


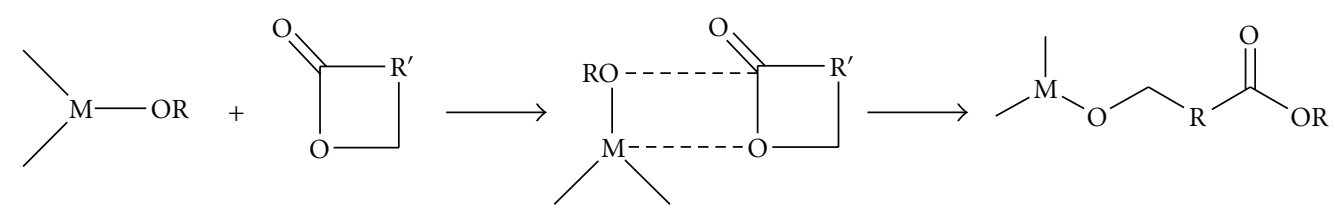

Scheme 4: Coordinate insertion mechanism of polymerization of lactones.

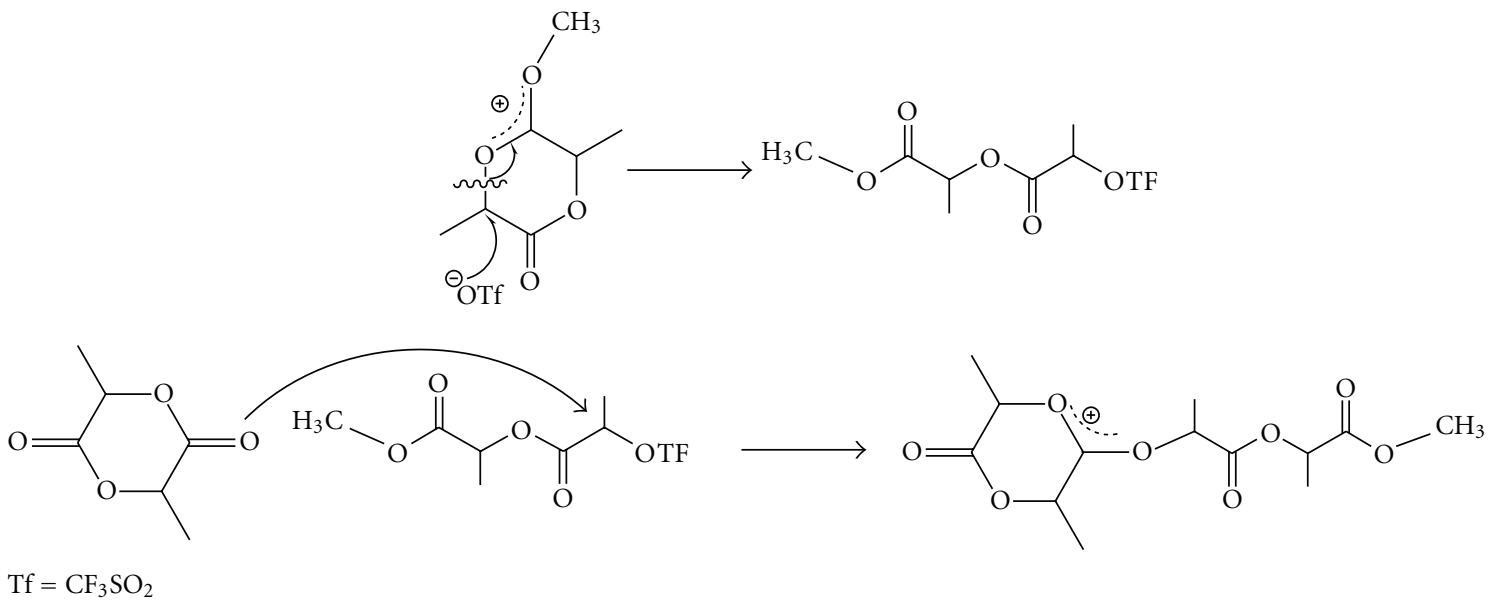

Scheme 5: Proposed pathway for cationic ring-opening polymerization of lactone.

and suggested similar activated monomer mechanism of propagation [153].

Atthoff and co-workers reported bulk ring opening polymerization of LA at $130^{\circ} \mathrm{C}$ using $5 \mathrm{~mol} \%$ diphenylammonium triflate (DPAT) as an acid-proton catalyst in ethanol as initiator [154]. Under these conditions, they were able to get PLA with molecular weight up to $12000 \mathrm{~g} / \mathrm{mol}$ with polydispersity 1.24 to 1.51 in 4 days. They also suggested that such a high polydispersity is due to transesterification with prolonged reaction time. The reaction proceeds through the same cationic activated monomer mechanism. The catalyst also been successfully utilized for the bulk and solution polymerization of various other lactones such as caprolactone, valerolactone and butyrolactone [155].

The acid catalysed cationic polymerization of lactones such as valerolactone or caprolactone can be performed using $\mathrm{HCL} \cdot \mathrm{Et}_{2} \mathrm{O}$ catalysts. Endo and co-workers utilized $\mathrm{HCL} \cdot \mathrm{Et}_{2} \mathrm{O}$ catalyst/alcohol initiator system for the controlled ring opening polymerization of $\mathrm{CL}$ and VL at room temperature and able to get polylactones with molecular weight up to $10000 \mathrm{~g} / \mathrm{mol}$ and polydispersity $1.08-1.27$ [156]. This catalyst system has been used for the controlled ring opening polymerization of lactones with the cyclic carbonate, 1,3dioxepane-2-one, to produce di and triblock copolymers with controlled molecular weights and narrow PDIs. Similarly, Kim and co-workers synthesised block copolymer of Poly(ethylene glycol) and poly(caprolactone) by the living ring opening polymerization $r$ of CL from a PEG initiator in the presence of the HCL. $\mathrm{Et}_{2} \mathrm{O}$ catalyst [157]. Jerome and co-workers were able to synthesize high molecular weight poly(valerolactone) having weight average molecular weight up to $50,000 \mathrm{~g} / \mathrm{mol}$ using the alcohol intiator/ $\mathrm{HCL} \cdot \mathrm{Et}_{2} \mathrm{O}$ system in dichloromethane [158]. However, under similar condition they were not able to synthesize PCL with molecular weight beyond 15,000 g/mol.

The polymerization of Lactones using the $\mathrm{HCL} \cdot \mathrm{Et}_{2} \mathrm{O}$ catalyst are proposed to proceed through an activatedmonomer mechanism.

Similarly, Organic acids such as tartaric acid, citric acid, lactic acid, fumaric acid and amino acid such as proline were successfully used for bulk and solution polymerization of various lactones [159-161]. The reaction proceeds in living controlled manner through the activated monomer mechanism through the cleavage of acyl-oxygen bond in all these systems. These systems were also efficiently utilized to synthesize polymer with various architecture such as three and four arm star polylactone [162-164]. Similarly solid supported acid catalyst can also be used for cationic ring opening polymerization of lactones but they offer little advantage over the conventional catalyst as they can't be regenerated and reused [165].

3.3.2. Anionic Ring Opening Polymerization. The effective initiators for anionic polymerization of lactones are alkali metals, alkali metal oxides, alkali metal naphthalenide complexes with crown ethers, and so forth. Depending upon the reaction conditions, the type of initiators, and the monomers, the polymerization may proceed either by a living or a nonliving mechanism. The reaction is initiated by nucleophilic attack of negatively charged initiator on the carbon of the carbonyl group or on the alkyl-oxygen, resulting in formation of linear polyester. The polymerization 


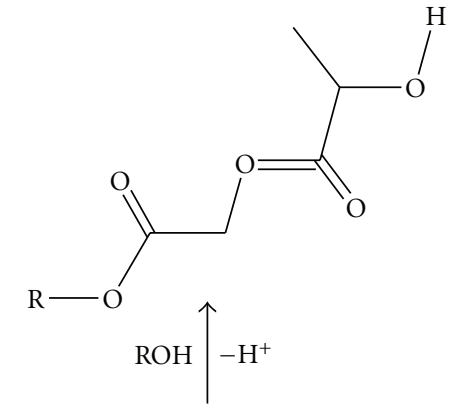<smiles>C=C1OC(C)C(O)C(=O)OC1C</smiles>

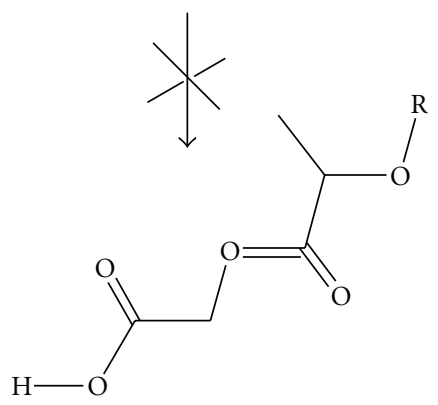

Scheme 6: Proposed Activated Monomer Pathway for Cationic ring-opening polymerization of lactone.

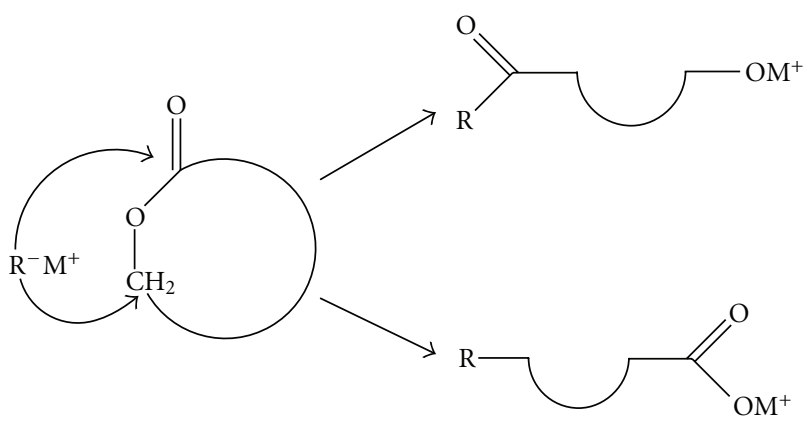

Scheme 7: Initiation of ring opening polymerization of Lactones by Anionic initiators.

of $\beta$-lactones proceeds through alkyl-oxygen or acyl-oxygen cleavage giving both carboxylate and alkoxide end groups (Scheme 7).

$\beta$-lactone polymerization initiated with weak bases proceeds via alkyl oxygen scission and carboxylate ions are the propagating species. There was a considerable disagreement regarding $\beta$-lactone polymerization using strong bases, that is, alkali metal alkoxides. It was proposed that acyl-oxygen scission takes place and the alcoholate ion is the propagating species. It was also claimed that propagation proceeds due to both alcoholate and carboxylate anions formed via alkyloxygen and acyl-oxygen scission.

Jedliński and co-workers [166-171] have done extensive studies on polymerization of $\beta$-lactone, that is, $\beta$-propiolactone and $\beta$-butyrolactone using potassium methoxide and potassium tert-butoxide complexes with 18-crown-6 as initiators. Their studies provided clear evidence that acyloxygen cleavage of the monomer takes place initially to yield potassium $\beta$-alkoxide ester, which in upon subsequent polymerization gives potassium hydroxide and unsaturated ester. Potassium hydroxide reacts with next $\beta$-lactone molecule inducing acyl-oxygen scission leading to the formation of carboxylate ion and hydroxyl end groups [169-171]. They have also reported living anionic ring opening polymerization of 4- and 5-membered ring lactones and obtained well define homopolymers and copolymers of high molecular mass [166] (Scheme 8).

In large lactones, such as $\epsilon$-caprolactone or lactide, the reaction proceeds by the acyl-oxygen scission only thereby leading to the formation of an alkoxide ion as the propagating species.

Large quantities of cyclic oligomers are formed on polymerization of $\epsilon$-CL using potassium tert-butoxide. This is primarily due to the backbiting reaction.

However, in the presence of lithium tert-butoxide in an apolar solvent, oligomer formation was significantly reduced. There are reports which suggest that the use lithium alkoxide is important in stereocontrol synthesis of PLA, however, this is not essential in PGA synthesis [172, 173] (Scheme 9).

Lithium species have successfully been applied to give significant stereocontrol in the polymerization of rac-lactide. Lithium tert-butoxide has been observed to produce heterotactic PLA with $\mathrm{P}_{r}$ (degree of stereoregularity expressed as the probability of racemic enchainment-syndiotactic) determined to be 0.76 in a polymerization carried out at room temperature which increases to 0.94 when polymerization carried out at $-20^{\circ} \mathrm{C}$ [174]. Recently, butyllithium has been employed in the synthesis of heterotactic PLA from raclactide and producing a moderately heterotatic polymer at $20^{\circ} \mathrm{C}\left(\mathrm{P}_{r}=0.72\right)$ [175]. Polymerization using magnesium tert-butoxide in identical conditions has been shown to produce slightly less heterotatic bias $\left(\mathrm{P}_{r}=0.63\right)$ [176].

Recently, Hild et al. discussed the synthesis a very new class of anionic aluminium alkoxide complexes supported by nontype diamido ether tridentate ligands and their use for the controlled ring-opening polymerization of Lactide [177].

3.3.3. Organometallic Compounds and Coordinate Insertion Mechanism of Ring Opening Polymerization. Catalysts of the type-like covalent metal alkoxides or carboxylates with vacant "d" orbitals has been extensively studied for the preparation of aliphatic esters with well-defined structure and architecture. These catalysts react as coordination initiators, not as anionic initiator in these polymerizations and are able to produce stereoregular polymers of narrow molecular weight distribution and controlled molecular mass, with well-defined end groups. The most widely used initiators 
<smiles>[R]C(O)C(=O)OC([Y8])C(=O)OCC(C)(C)C(=O)OC</smiles>

Scheme 8: Anionic polymerization of lactone showing acyl-oxygen scisson.

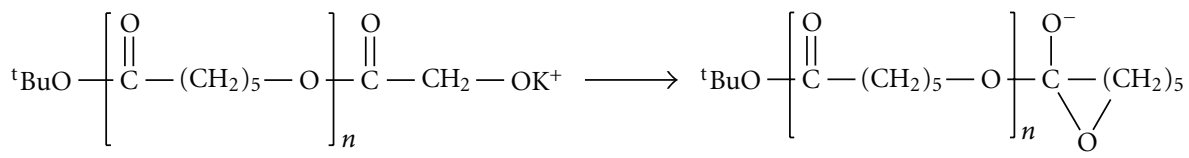

$$
\begin{aligned}
& \downarrow
\end{aligned}
$$

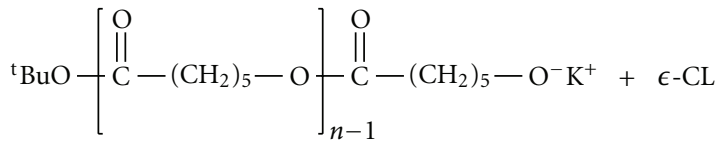

SCHeme 9: Backbitting (intramolecular transesterification) during ring opening polymerization of $\epsilon$-CL.<smiles>[R]OCCOCCC([R])=O</smiles>

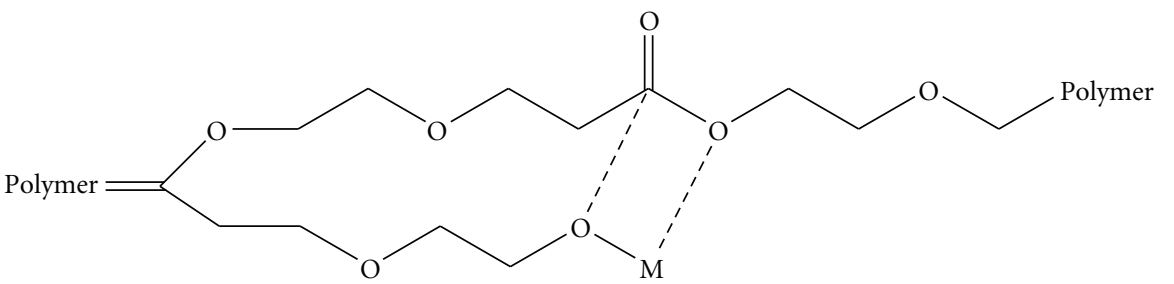

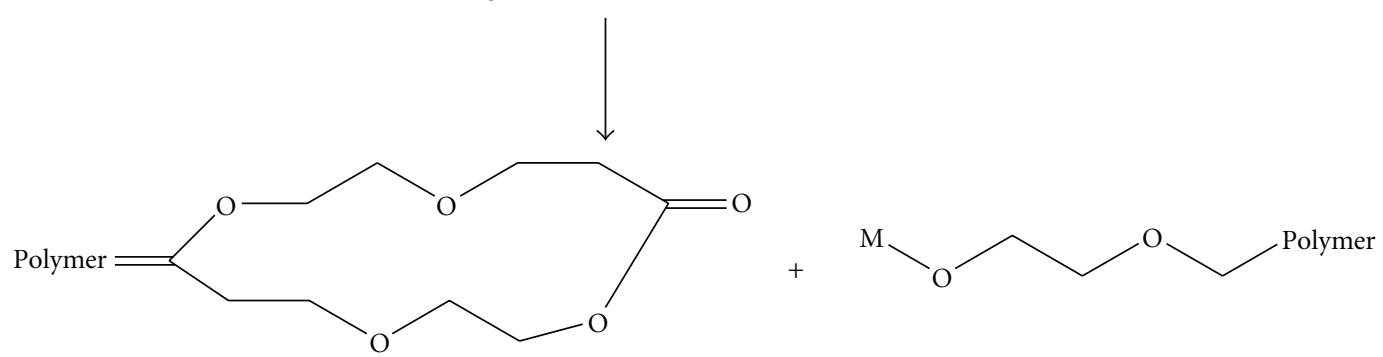

Scheme 10: Intra- and intermolecular transesterificiation reactions during ring opening polymerization. 


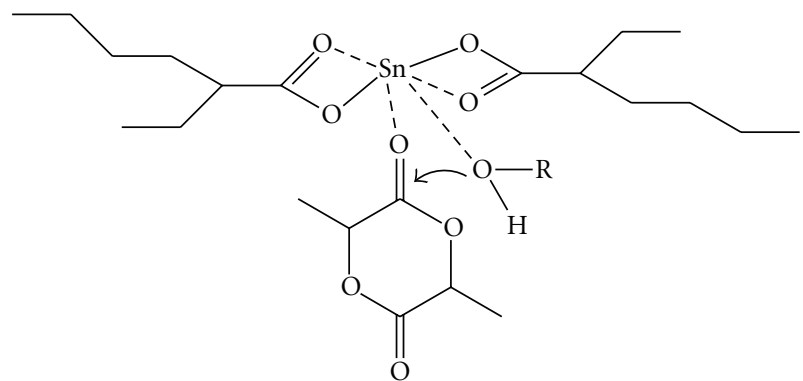

Scheme 11: Activated monomer mechanism for ring-opening polymerization of lactones.

$\mathrm{Sn}(\mathrm{Oct})_{2}+\mathrm{R}-\mathrm{OH} \rightleftharpoons \mathrm{OctSnOR}+\mathrm{OctH}$

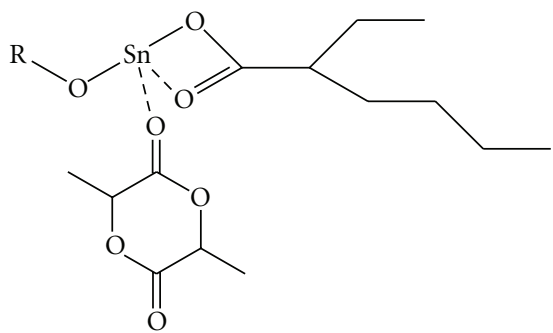

Scheme 12: Tin alkoxide complex initiated polymerization of Lactones.

of this class are various aluminium and tin alkoxides or carboxylates.

In comparison to alkoxides, the carboxylates are weaker nucleopiles and behave more like a catalyst rather than an initiator. Metal carboxylates are therefore used together with an active hydrogen compound (e.g., alcohols) as coinitiators. The polymerization proceeds via acyl-oxygen cleavage of the lactone with insertion of the monomer into the metal-oxygen bond of initiator [178-183]. The coordination of the exocyclic oxygen to the metal results in the polarization and makes the carbonyl carbon of the monomer more susceptible for nucleophilic attack.

Ring-opening polymerization of lactones with these organometallic initiators at high temperatures or long reaction times leads to both inter as well as intramolecular transesterification reactions. Both types of transesterification reactions lead to an increase in polydispersity of the polyester (Scheme 10).

The reaction parameters that influence the transesterification reactions are temperature, reaction time, the type and concentration of catalyst or initiator, and the nature of the lactone or lactide [184]. For example, in the polymerization of CL or LA initiated with $\mathrm{SnOct}_{2} / \mathrm{BuOH}$ or $\mathrm{ZnOct}_{2} / \mathrm{BuOH}$, the end groups in originally formed macromolecules changed to fully esterified $\mathrm{BuO}(\mathrm{O}) \mathrm{C}-\mathrm{PLA}-\mathrm{Oct}$ and $\mathrm{HO}(\mathrm{O}) \mathrm{C}-\mathrm{PLA}-\mathrm{Oct}$ chains on increasing the duration of polymerization [185].

Some of the catalyst/initiators decompose at elevated temperatures thereby influencing the rate of ring opening polymerization and increasing the side reactions. The formation of octanoic acid was reported by Kricheldorf et al. [186], when tin (II) 2-ethylhexanoate was heated above $100^{\circ} \mathrm{C}$. The acid thus liberated may bring about the esterification of alcohol (active hydrogen co-initiator) leading to the formation of water, which may react with $\mathrm{SnOct}_{2}$ to form stannoxanes and tin hydroxides. Under such conditions it would be difficult to control the molecular mass and side reactions because the presence of water or other hydroxyl compounds is likely to initiate the polymerization. The relative reactivity of different metal alkoxide initiators for transesterification reaction depends on the metal and is lowest for aluminium alkoxides as follows:

$\mathrm{Al}(\mathrm{OR})_{3}<\mathrm{Zn}(\mathrm{OR})_{2}<\mathrm{Ti}(\mathrm{OR})_{4}<\mathrm{Bu}_{3} \mathrm{SnOR}<\mathrm{Bu}_{2} \mathrm{Sn}(\mathrm{OR})_{2}$.

The flexibility of the backbone polymer also affects the side reactions. Higher the flexibility higher will be the transesterification reaction. For example the lactide configuration (D,L- or L-lactide) influence the extent of transesterification reactions during ring opening polymerization. Higher side reactions were observed in D,L-Lactide compared to those in L-Lactide and have been attributed to the flexibility of the former due to the atactic nature of the backbone [187]. Similarly when $\epsilon$-CL and L-Lactide is block copolymerized, the sequence of monomer addition is important. $\mathrm{AB}$ block copolymers have been prepared by ring opening polymerization if $\epsilon$-CL is polymerized first. However, a totally random copolymer is obtained if L-LA block is prepared first.

In most metal alkoxides there is formation of aggregates in solution at low temperature and the group involved in the coordination aggregation will not participate in propagation of reaction, thus, an induction period is observed in which the initiator rearranges to form the active species for polymerization. The formation of the aggregates depends on the solvent polarity, the nature of substituents, and the presence of coordinative ligands such as amines and alcohols. In polar and nucleophilic solvents, these agglomerates get solvated and the reaction becomes fully controlled.

Tin(II) 2-ethylhexanoate (Figure 4) is the most commonly used initiator/catalyst for ring opening polymerization [188-201]. It is a very effective and versatile catalyst, which is easy to handle and is soluble in common organic solvents and lactones. The Food and Drug Administration has approved it as a food additive. It is also known as stannous octoate $\left(\mathrm{SnOct}_{2}\right)$. As mentioned earlier, ring opening polymerization reaction with $\mathrm{SnOct}_{2}$ is carried out in the presence of active hydrogen compounds [202, 203]. If no active hydrogen compound is added, the actual initiating species may be hydrogen containing impurity [203]. The polymerization mechanism with this is rather complex and a number of mechanisms has been proposed earlier for this [204, 205].

In the activated monomer mechanism, it was proposed that the monomer is coordinated with the catalyst and is activated. The ring opening polymerization then proceeds via a nucleophilic attack of alcohol leading to the insertion of monomer into metal-oxygen bond by rearrangement of the electrons (Scheme 11). 
<smiles>CC(=O)COC(C)(C)COC(=O)CO</smiles>

Low molecular weight polymer, $\mathrm{Mw}=2000$ to 10000

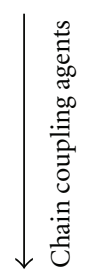<smiles>CC(C)(CO)OCC(=O)OCC(=O)O</smiles>

High molecular weight polymer, $\mathrm{Mw}>100,000$

Scheme 13: General scheme for oligomer synthesis and chain coupling reaction for polyhydroxyesters.

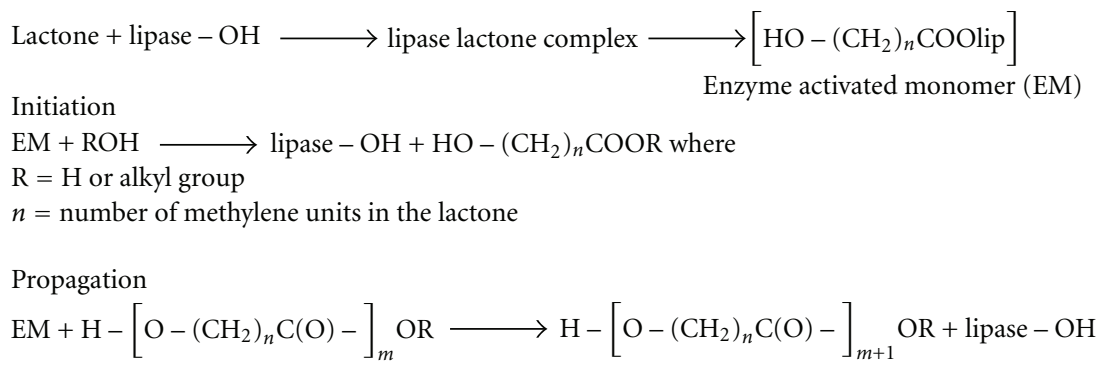
Scheme 14: Mechanism of Lipase Catalyzed Polymerization of Lactones.

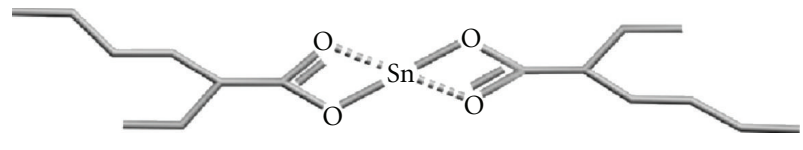

Figure 4: Tin (II) ethylhexanoate.

The alcohol functionality and the monomer are both coordinated to the $\mathrm{SnOct}_{2}$ complex during propagation. The reaction is terminated by hydrolysis forming a hydroxyl end group.

An alternative mechanism was proposed by Penezek and co-workers, suggesting that when $\mathrm{SnOct}_{2}$ is mixed with an alcohol, an initiating complex is formed prior to polymerization. The establishment of equilibrium between $\mathrm{SnOct}_{2}$ and alcohol results in the liberation of acid from the catalyst. The tin alkoxide complex thus formed then initiates the polymerization (Scheme 12).
The support to this mechanism was provided by an experiment showing an increased in the rate of ring opening polymerization by addition of butanol as initiator to distilled SnOct $_{2}$ [206]. Further support to this mechanism was obtained by the addition of octanoic acid to tin (II) butoxide. The reaction rate at certain ratios of octanoic acid to tin (II) butoxide was identical to that obtained by adding butanol to $\mathrm{SnOct}_{2}$. The presence of tin alkoxide has recently been detected by MALDI-TOF experiments [207, 208]. The ring opening polymerization of lactides with $\mathrm{SnOct}_{2}$ is fairly slow. Addition of triphenyl phosphine not only increases the rate but also suppresses the undesirable intramolecular side reaction [209]. Recently, Ryner et al. [210] described ring opening polymerization of dioxane and L-Lactide using $\mathrm{SnOct}_{2}$ with their theoretical study. Their results were concurrent and supporting to coordination-insertion mechanism initiated by a tin-alkoxide species formed prior to ring opening polymerization. 
Tin (II) alkoxides such such as tin (II) butoxide $\left[\mathrm{Sn}(\mathrm{OBu})_{2}\right]$ exist in monomeric and dimeric forms. The polymerization of lactones with tin alkoxides is believed to follow the coordination-insertion mechanism. The ring opening polymerization of lactones proceeds by acyl-oxygen cleavage with retention of configuration. $\mathrm{Sn}(\mathrm{OBu})_{2}$ is an extremely reactive initiator with reaction rates comparable with that of ring opening polymerization initiated by rare earth metal alkoxides [210]. Complete conversion is observed after 20 hours in $\mathrm{Sn}(\mathrm{Oct})_{2}$ initiated ring opening polymerization of lactones whereas the same reaction with $\mathrm{Sn}(\mathrm{OBu})_{2}$ only takes few minutes. Ring opening polymerization of L-Lactide with $\mathrm{Sn}(\mathrm{OBu})_{2}$ gives a stereoregular polyester and provide full control of molecular mass $\left(10^{3}-\right.$ $\left.10^{6} \mathrm{~g} / \mathrm{mol}\right)$.

Tin (IV) Alkoxides such dibutylin oxides as well as its alkoxy derivatives have been successfully employed for the ring opening polymerization of lactones. $\mathrm{Bu}_{2} \mathrm{SnO}$ dissolved in terbutylin is believed to be the main initiator in the polymerization of $\epsilon$-CL [211]. Tin (IV) alkoxide with linear, cyclic and spirocyclic functional groups other than hydroxyls can be easily prepared from corresponding functional group containing tin oxide or tin chloride by reacting with monofunctional or difunctional alcohols. Tributyltin methoxide and dibutyltin dimethoxide have been used for the initiation of bulk polymerization of lactones and lactides at $100^{\circ} \mathrm{C}-120^{\circ} \mathrm{C}[212,213]$. Under these reaction conditions, controlled polymerization was not possible, and polymers of high polydispersity index were produced. High yield and narrow molecular mass distribution was obtained by using solution polymerization in dichloromethane at $40^{\circ} \mathrm{C}$ [214]. Careful purification of these initiators is necessary for achieving controlled ring opening polymerization. The tin alkoxides offer far better control of the polymerization than $\mathrm{SnOct}_{2}$. They initiate controlled ring opening polymerization in solutions at relatively low temperatures. Almost $100 \%$ conversion was obtained in the living macrocyclic polymerization of $\epsilon$-CL in bulk at $80^{\circ} \mathrm{C}$ with 2,2-dibutyl-2stanna-1,3-dioxepane as an initiator [215].

A two steps coordination insertion mechanism has been proposed for tin (IV) alkoxide initiators $\left(\mathrm{SnMe}_{3} \mathrm{MeO}\right.$, $\left.\mathrm{SnMe}_{2}(\mathrm{MeO})_{2}\right)$ on the basis of their study of ring opening polymerization of dioxane and Glycolide. In the first step, the nucleophilic attack of the alkoxide of the initiator on the carbonyl carbon of the monomer takes place. The second step involves the acyl-oxygen cleavage of the monomer [216].

Recently, Albertsson and co-workers have reported the use of cyclic tin (IV) alkoxide initiators for ring opening polymerization of lactones [214, 217, 218]. These alkoxides are hydrolytically more stable compared to aluminium counterparts and are consequently easier to handle and to use in the polymerization. The cyclic tin alkoxides such as 1,1,6,6-tetra-n-butyl-1,6-distanna-2,5,7,10-tetra-oxacyclodecane, 1,1-di-n-butyl-stanna-2,7-dioxacyclo-4-heptene, and 9.9.20.20-tetrabutyl-8, 10,19,21-tetraoxa-9,20-distannadispiro [5.5.5.5] docosa-2, 14-diene, and so forth. exist in an equilibrium with their monomeric and dimeric forms. Kricheldorf and Eggerstedt [216] reported for the first time spirocyclic tin(IV) alkoxides. A four-armed spirocyclic tin (IV) alkoxide was synthesized by condensation of hydroxyethylated pentaerythritol with dibutyltin dimethoxide for initiating ring opening polymerization of $\epsilon$-CL and $\beta$-D,L-butyrolactone. High molecular mass $\operatorname{poly}(\epsilon-\mathrm{CL})$ with a polydispersity index of $<2$ could be obtained using this initiator. Stridsberg [219] and co-workers have used spirocyclic tin alkoxides for the solution polymerization of L-lactide. Initiation was instantaneous, conversion was very high and molecular mass distribution was less than 1.13. Zhang and Liu reported the synthesis of molecular weight controllable poly(lactic acid) using 1,8-diazabicylco (5.4.0.)-7-undecene as an organocatalyst and isopropanal as an initiator [220].

Aluminium alkoxides are the most extensively investigated alkoxides for the initiation of ring opening polymerization of lactones and lactides [221-229]. Both aluminium trialkoxides $(\mathrm{AlOR})_{3}$ and aluminium alkyl dialkoxides have been used for the initiation. Teyessie and co-workers first reported the successful use of these initiators for ring opening polymerization. These alkoxides propagate the reaction through coordination insertion mechanism. Aluminium isopropoxide coordinates to the exocyclic carbonyl oxygen followed by acyl-oxygen cleavage leading to an isopropyl ester group. Termination of growing chain with dilute $\mathrm{HCl}$ leads to the formation of a hydroxyl end group. The propagation is characteristed by almost complete absence of transesterification reactions up to a very high percentage conversion with a narrow molecular mass distribution and an increase in DP with an increase in monomer to initiator ratio [230-232]. In most case the polymerization is generally carried out in toluene or THF solution at low temperature $\left(0-25^{\circ} \mathrm{C}\right)$. Freshly distilled aluminium isopropoxide consists mainly of trimers and is more reactive initiator of ring opening polymerization. Under these conditions, three chains grow per aluminium atom. According to the kinetic study of Albertsson and co-workers [221, 224, 226] and Duda and Penczek [233-236], a first order kinetics with respect to monomer and initiator was observed for ring opening polymerization of lactones and lactides using aluminium alkoxide as an initiator. Inoue and Shimasaki et al. reported initiators based on $\alpha, \beta, \gamma, \delta$ derivatives of tetraphenylporphinato-aluminium for the polymerization of $\epsilon$-CL, $\beta$-lactones and lactides $[237,238]$.

A new classes of metal alkoxides, Lanthanide alkoxides such as yttrium isopropoxide and yttrium 3-oxapentoxide also being used for the ring opening polymerization of $\epsilon$ $\mathrm{CL}$, and lactides as reported by McLain and Drysdale [239, 240]. The activity of these catalysts is much higher than the aluminium alkoxides, especially in lactide polymerizations [241, 242]. Lanthanide compounds such as yttrium and lanthanide alkoxides, as well as Sm and Lu complexes yield high molecular weight polyesters under relatively mild conditions. Rapid polymerization of $\epsilon$-CL at room temperature was observed when yttrium alkoxide was used as an initiator $[243,244]$. Stevels et al. have used in situ generated yttrium alkoxides as initiators for $\epsilon$-CL and $\delta$-VL $[245,246]$.

Titanium alkoxides another group of alkoxides also have shown good catalytic activity somewhat similar to tin alkoxides for the polymerization of lactones. Recently, 
Kim and co-workers utilized these titanium alkoxides for the bulk polymerization of L-Lactide and rac-Lactide at $130^{\circ} \mathrm{C}$ [247-249]. Another titanium based-agent, titanium chloride complex play the same role as an alkoxides as reported by Takashima et al. [250]. They also theorized for utilizing the titanium alkoxide as in early stage of reaction alkoxide group dissociate from the complex for initiating the reaction and provide a means of controlling the molecular weight by functioning as an end group. Alkoxy titanatranes seemed well-suited to these purposes because they possess a transannular $\mathrm{Ti}-\mathrm{N}$ bond that could potentially labilize the trans axial OR group.

Novel N-Heterocyclic carbene derivatives as organocatalysts for the zwitterionic ring-opening polymerization of lactide to cyclic poly(lactic acid) had been tested by Culkin et al. [251].

\subsubsection{Biocompatible Organometallic Initiators/Catalysts. Tin} and aluminium being the most widely used organometallic initiators for ring opening polymerization of lactones and even though the $\mathrm{Sn}$ (II)-2-ethyl hexanoate have been approved by FDA for use in food additive but it still possess toxicity [252]. It has been reported that $\mathrm{Sn}(\mathrm{Oct})_{2}$ is not removed completely by a purification method involving dissolution and precipitation below as residual level of $306 \mathrm{ppm}$ in PLA [253]. In preview of this there is an essential requirement to search for metal containing initiators, which are not harmful for the human organisms.

Zinc based catalysts are less toxic and have been used in the ring opening polymerization of lactones. In Industry, Zinc metal or stannous octoate are two simultaneously used catalysts for the polymerization of D,L-lactide. Zinc based catalyst used in pharmaceutical and biomedical applications include zinc metal, zinc octoate, zinc stearate, zinc salicylate and zinc lactate [254-258]. The polymerization rates, extent of conversion, molecular weights, and transesterification reaction are different in zinc metal initiated polymerization of lactide compared to $\mathrm{Sn}(\mathrm{Oct})_{2}$ initiated polymerization $[255,256,258] . \mathrm{Sn}(\mathrm{Oct})_{2}$ initiated polymerization was much faster and yielded high molecular weight polymers with no detectable residual monomer and lower transesterification reactions [258]. However, the residual tin in polylactide was in the range of 300-400 ppm, whereas the level of zinc was in the range of 20-40 ppm. The properties of the polymers such as hydrolytic stability, hydrophilicity prepared by these two initiators was also different [259].

Kricheldorf et al. [260-262] reported polymerization of 1,4-dioxane as well as D,L-Lactide using Zinc (II)-L-lactate $\left(\mathrm{ZnLac}_{2}\right)$. The rate of $\mathrm{ZnLac}_{2}$ initiated polymerization were relatively slower than $\mathrm{Sn}(\mathrm{Oct})_{2}$ initiated polymerization. Similar other metals such as $\mathrm{Ca}, \mathrm{Mg}$ and $\mathrm{Fe}$ have also been investigated for their use as initiators/catalysts. Calcium acetylacetonate [263] was found to yield high molecular weight polymer of glycolide and its copolymer with lactide or $\epsilon$-CL. Recently, in-situ generated calcium alkoxides have been reported to use in fast and living ring opening polymerization of L-lactide [264]. Kriechoeldorf et al. carried out copolymerization of glycolide and $\epsilon-\mathrm{CL}$ in the presence of iron compounds [265]. Finna and Albertsson [266] have recently published the use of germanium coumpounds as initiators for lactide polymerization, because derivatives of germanium are less toxic than tin compounds.

\section{Conclusion}

The biodegradable polymers are indispensable in drug delivery due to their unrivalled physicochemical properties. These physicochemical properties have a significant effect on the drug delivery system right since the start from their processing till the end of finished products, that is, pharmacological effect. Every drug molecule has different physicochemical and pharmacokinetic profile, thus, require a perfect set of conditions for the formulation, stability and release kinetics. To achieve these set of conditions we require specific polymer with desired physicochemical properties.

The physicochemical properties of polymers lies in the various architectural elements, that is, backbone, functional fidelity, cross-linkages. Poly(glycolic acid) exit in various crystalline form varying from highly amorphous to crystalline state and can be manipulated through the change in basic structural element and processing methodologies. The review has discussed the key structural elements as derived by using highly sophisticated techniques, that is, X-ray crystallographic structure data. The synthetic methodologies discussed in the present review can be applied to synthesize the end product with desired architechtural qualities affecting the entrapment efficiency, rate of degradation, stability of finished product, biocompatibility and so forth.

\section{References}

[1] R. K. Kulkarni, E. G. Moore, A. F. Hegyeli, and F. Leonard, "Biodegradable poly(lactic acid) polymers," Journal of Biomedical Materials Research, vol. 5, no. 3, pp. 169-181, 1971.

[2] R. A. Miller, J. M. Brady, and D. E. Cutright, "Degradation rates of oral resorbable implants (polylactates and polyglycolates): rate modification with changes in PLA/PGA copolymer ratios," Journal of Biomedical Materials Research, vol. 11, no. 5, pp. 711-719, 1977.

[3] Based on a lecture presented at the Fourth Annual Biomaterial Symposium, Clemson University, Clemson, South Sarolina, Getter, 1972.

[4] T. M. Jackanicz, H. A. Nash, D. L. Wise, and J. B. Gregory, "Polylactic acid as a biodegradable carrier for contraceptive steroids," Contraception, vol. 8, no. 3, pp. 227-234, 1973.

[5] L. C. Anderson, D. L. Wise, and J. F. Howes, "An injectable sustained release fertility control system," Contraception, vol. 13, no. 3, pp. 375-384, 1976.

[6] E. E. Schmitt and M. A. Epstein,US Patent 3718150, 1971.

[7] A. D. Schwope, D. L. Wise, and J. F. Howes, "Lactic/glycolic acid polymers as narcotic antagonist delivery systems," Life Sciences, vol. 17, no. 12, pp. 1877-1886, 1975.

[8] E. E. Schmitt, M. Epstein, and R. A. Polistina, "Process for polymerizing a glycolide," US Patent $3422871,1969$.

[9] E. E. Schmitt and R. A. Polistina, "Surgical sutures," US Patent 3297033, 1967.

[10] E. J. Frazza and E. E. Schmitt, "A new absorbable suture," Journal of Biomedical Materials Research, vol. 5, no. 2, pp. 43$58,1971$. 
[11] G. S. Kumar, V. Kalpagam, and U. S. Nandi, "Biodegradable polymers: prospects, problems, and progress," Reviews in Macromolecular Chemistry and Physics, vol. C22, no. 2, pp. 225-260, 1982.

[12] D. F. Williams, "Biodegradation of surgical polymers," Journal of Materials Science, vol. 17, no. 5, pp. 1233-1246, 1982.

[13] D. K. Gilding and A. M. Reed, "Biodegradable polymers for use in surgery-polyglycolic/poly(actic acid) homo- and copolymers: 1," Polymer, vol. 20, no. 12, pp. 1459-1464, 1979.

[14] L. H. Sperling, Introduction to Physical Polymer Science, Wiley-Interscience, New York, NY, USA, 3rd edition, 2001.

[15] R. Auras, B. Harte, and S. Selke, "An overview of polylactides as packaging materials," Macromolecular Bioscience, vol. 4, no. 9, pp. 835-864, 2004.

[16] K. M. Benabdillah, M. Boustta, J. Coudane, and M. Vert, "Can the glass transition temperature of PLA polymers be increased?" in ACS Symposium Series, C. Scholz and R. A. Gross, Eds., vol. 764, pp. 200-220, American Chemical Society, Washington, DC, USA, 2000.

[17] P.-G. de Gennes, Scaling Concepts in Polymer Physics, Cornell University Press, Ithaca, NY, USA, 1979.

[18] S. B. Clough, X. F. Sun, S. K. Tripathy, and G. L. Baker, "Molecular dynamics simulation of substituted polyacetylenes," Macromolecules, vol. 24, no. 15, pp. 4264-4269, 1991.

[19] T. Masuda and T. Higashimura, "Polyacetylenes with substituents: their synthesis and properties," Advances in Polymer Science, vol. 81, pp. 121-165, 1986.

[20] S. S. Rogers and L. Mandelkern, "Glass formation in polymers. I. The glass transitions of the poly-(n-alkyl methacrylates)," Journal of Physical Chemistry, vol. 61, no. 7, pp. 985-990, 1957.

[21] Y.-B. Lim, Y. H. Choi, and J.-S. Park, "A self-destroying polycationic polymer: biodegradable poly(4-hydroxy-L-proline ester)," Journal of the American Chemical Society, vol. 121, no. 24, pp. 5633-5639, 1999.

[22] L. M. Pratt and C. C. Chu, "Biodegradable polyesters: theoretical modeling of degradation," in The Polymeric Materials Encyclopedia, J. C. Salamone, Ed., pp. 583-588, CRC Press, Boca Raton, Fla, USA, 1996.

[23] M. Mochizuki, K. Mukai, K. Yamada, N. Ichise, S. Murase, and Y. Iwaya, "Structural effects upon enzymatic hydrolysis of poly(butylene succinate-co-ethylene succinate)s," Macromolecules, vol. 30, no. 24, pp. 7403-7407, 1997.

[24] M. Mochizuki, M. Hirano, Y. Kanmuri, and K. Kudo, "Hydrolysis of polycaprolactone fibers by lipase: effects of draw ratio on enzymatic degradation," Journal of Applied Polymer Science, vol. 55, no. 2, pp. 289-296, 1995.

[25] K. Cho, J. Lee, and K. Kwon, "Hydrolytic degradation behavior of poly(butylene succinate)s with different crystalline morphologies," Journal of Applied Polymer Science, vol. 79, no. 6, pp. 1025-1033, 2001.

[26] M. Nagata, T. Machida, W. Sakai, and N. Tsutsumi, "Synthesis, characterization, and enzymatic degradation of network aliphatic copolyesters," Journal of Polymer Science Part A, vol. 37, no. 13, pp. 2005-2011, 1999.

[27] J. A. Ratto, P. J. Stenhouse, M. Auerbach, J. Mitchell, and R. Farrell, "Processing, performance and biodegradability of a thermoplastic aliphatic polyester/starch system," Polymer, vol. 40, no. 24, pp. 6777-6788, 1999.

[28] U. Witt, R. J. Müller, J. Augusta, H. Widdecke, and W. D. Deckwer, "Synthesis, properties and biodegradability of polyesters based on 1,3-propanediol," Macromolecular Chemistry and Physics, vol. 195, no. 2, pp. 793-802, 1994.
[29] D. A. Wood, International Journal of Pharmaceutics, vol. 7, p. $11,1980$.

[30] D. Larobina, G. Mensitieri, M. J. Kipper, and B. Narasimhan, "Mechanistic understanding of degradation in bioerodible polymers for drug delivery," AIChE Journal, vol. 48, no. 12, pp. 2960-2970, 2002.

[31] T. G. Park, S. Cohen, and R. Langer, "Poly(L-lactic acid)/pluronic blends: characterization of phase separation behavior, degradation, and morphology and use as proteinreleasing matrices," Macromolecules, vol. 25, no. 1, pp. 116122, 1992.

[32] E. E. Schmitt, M. Epstein, and R. A. Polistina, "Process for polymerizing a glycolide,” US Patent 3442871, 1969.

[33] E. E. Schmitt and R. A. Polistina, "Surgical sutures," US Patent 3297033, 1967.

[34] E. J. Frazza and E. E. Schmitt, "A new absorbable suture," Journal of Biomedical Materials Research, vol. 5, no. 2, pp. 43$58,1971$.

[35] A. Glick and J. B. Mcpherson Jr., "Absorbable polyglycolic acid suture of enhanced in-vivo strength retention," US Patent 3626948, 1971.

[36] C. S. Fuller and C. L. Erickson, "An X-ray study of some linear polyesters," Journal of the American Chemical Society, vol. 59, no. 2, pp. 344-351, 1937.

[37] C. S. Fuller, C. J. Frosch, and N. R. Pape, "Chain structure of linear polyesters-trimethylene glycol series," Journal of the American Chemical Society, vol. 64, pp. 154-160, 1942.

[38] C. S. Fuller and C. J. Frosch, "Further investigation of the chain structure of linear polyesters," Journal of Physical Chemistry, vol. 43, no. 3, pp. 323-334, 1939.

[39] C. S. Fuller and C. J. Frosch, "X-ray investigation of the decamethylene series of polyesters," Journal of the American Chemical Society, vol. 61, no. 10, pp. 2575-2580, 1939.

[40] C. S. Fuller, "The investigation of synthetic linear polymers by X-rays," Chemical Reviews, vol. 26, no. 2, pp. 143-167, 1940.

[41] A. Turner-Jones and C. W. Bunn, "The crystal structure of polyethylene adipate and polyethylene suberate," Acta Crystallographica, vol. 15, no. 2, pp. 105-113, 1962.

[42] H. Hirono, G. Wasai, T. Mitsueda, and J. Furukaw, Journal of the Chemical Society of Japan, vol. 67, p. 604, 1964.

[43] Y. Chatani, K. Suehiro, Y. Okita, H. Tadokoro, and K. Chujo, "Structural studies of polyesters. I. Crystal structure of polyglycolide," Die Makromolekulare Chemie, vol. 113, no. 1, pp. 215-229, 1968.

[44] D. F. Williams, "Biodegradation of surgical polymers," Journal of Materials Science, vol. 17, no. 5, pp. 1233-1246, 1982.

[45] D. K. Gilding and A. M. Reed, "Biodegradable polymers for use in surgery-polyglycolic/poly(actic acid) homo- and copolymers: 1," Polymer, vol. 20, no. 12, pp. 1459-1464, 1979.

[46] D. A. Deprospero and E. E. Schmitt, "Stable glycolide and lactide compositions,” US Patent 3597449, 1971.

[47] Am.Cyanamid Co., Frensh Patent 1563261, 1969.

[48] Am.Cyanamid Co., Frensh Patent 1512182, 1967.

[49] H. Dardik, I. Dardik, and H. Laufman, "Clinical use of polyglycolic acid polymer as a new absorbable synthetic suture," The American Journal of Surgery, vol. 121, no. 6, pp. 656-660, 1971.

[50] D. C. Miln, J. O'Connor, and R. Dalling, "The use of polyglycolic acid suture in gastro-intestinal anastomosis," Scottish Medical Journal, vol. 17, no. 3, pp. 108-110, 1972.

[51] D. Wasserman, US Patent 1375008, 1971. 
[52] D. Wasserman and C. Versfelt, "Use of stannous octoate catalyst in the manufacture of L(-)lactide-glycolide copolymer sutures," US Patent 3839297, 1975.

[53] R. A. Miller, J. M. Brady, and D. E. Cutright, "Degradation rates of oral resorbable implants (polylactates and polyglycolates): rate modification with changes in PLA/PGA copolymer ratios," Journal of Biomedical Materials Research, vol. 11, no. 5, pp. 711-719, 1977.

[54] D. L. Wise, G. J. McCormick, G. P. Willet, and L. C. Anderson, "Sustained release of an antimalarial drug using a copolymer of glycolic/lactic acid," Life Sciences, vol. 19, no. 6, pp. 867874, 1976.

[55] T. Sato, M. Kanke, H. G. Schroeder, and P. P. DeLuca, "Porous biodegradable microspheres for controlled drug delivery. I. Assessment of processing conditions and solvent removal techniques," Pharmaceutical Research, vol. 5, no. 1, pp. 2130, 1988.

[56] M. P. Redmon, A. J. Hickey, and P. P. DeLuca, "Prednisolone21-acetate poly(glycolic acid) microspheres: influence of matrix characteristics on release," Journal of Controlled Release, vol. 9, no. 2, pp. 99-109, 1989.

[57] A. M. Hazrati, S. Akrawi, A. J. Hickey, P. Wedlund, J. Macdonald, and P. P. DeLuca, "Tissue distribution of indium111 labeled poly(glycolic acid) matrices following jugular and hepatic portal vein administration," Journal of Controlled Release, vol. 9, no. 3, pp. 205-214, 1989.

[58] X. Jigang, C. Gonglin, H. Guoyi, and Z. Qingzhang, Hecheng Xianwei Gongye, vol. 29, p. 10, 2006.

[59] J. Nieuwenhuis, "Synthesis of polylactides, polyglycolides and their copolymers," Clinical Materials, vol. 10, no. 1-2, pp. 5967, 1992.

[60] P. Peng-gang, L. Guang-lin, Z. Zheng-yu, and W. Hong-tao, Zhongguo Jiaonianji, vol. 16, p. 14, 2007.

[61] Z. Wangxi, Suliao Gongye, vol. 34, p. 1, 2006.

[62] Z. Lingchong, L. Wenming, X. Qing, and L. Fengyi, Suliao Gongye, vol. 34, p. 8, 2006.

[63] T. Kaiguang, H. Guanbao, and Y. Zelin, Hecheng Xianwei Gongye, vol. 30, p. 29, 2007.

[64] M. Qiang, Y. Qing-fang, and Y. Jan-yan, Gaofenzi Cailiao Kexue Yu Gongcheng, vol. 20, p. 21, 2004.

[65] J. Ren and Q.-F. Wang, "Synthesis research of biodegradable polylactide and co-polylactide," Jianzhu Cailiao Xuebao, vol. 6, no. 4, p. 397, 2003.

[66] W. Yuanliang and Z. Jainhua, Chongquing Daxue Xuebao, Ziran Kexueban, vol. 19, p. 112, 1996.

[67] W. Zheng, W. Ting, and Z. Xueming, Lizi Jiahuan Yu Xifu, vol. 16, p. 311, 2000.

[68] K. Takahashi, I. Taniguchi, M. Miyamoto, and Y. Kimura, "Melt/solid polycondensation of glycolic acid to obtain highmolecular-weight poly(glycolic acid)," Polymer, vol. 41, no. 24, pp. 8725-8728, 2000.

[69] W. Zhe, N. Hong-zhe, and L. Xi-jing, Chongquing Daxue Xuebao, Ziran Kexueban, vol. 26, p. 112, 2005.

[70] W. Zhaoyang, Z. Yaoming, Y. Yurong, W. Fang, Y. Gexin, and W. Jun, Hecheng Xianwei Gongye, vol. 27, p. 1, 2004.

[71] K. Enomoto, M. Ajioka, and A. Yamaguchi, "Polyhydroxycarboxylic acid and preparation process thereof," US Patent 5310865, 1994.

[72] T. Kashima, T. Kameoka, C. Higuchi, M. Ajioka, and A. Yamaguchi, "Aliphatic polyester and preparation process thereof," US Patent 5428126, 1995.

[73] F. Ichikawa, M. Kobayashi, M. Ohta, Y. Yoshida, S. Obuchi, and H. Itoh, "Process for preparing polyhydroxycarboxylic acid," US Patent 5440008, 1995.
[74] M. Ohta, S. Obuchi, and Y. Yoshida, "Preparation process of polyhydroxycarboxylic acid," US Patent 5444143, 1995.

[75] M. Ajioka, K. Enomoto, K. Suzuki, and A. Yamaguchi, "The basic properties of poly(lactic acid) produced by the direct condensation polymerization of lactic acid," Journal of Environmental Polymer Degradation, vol. 3, no. 4, pp. 225234, 1995.

[76] M. Ajioka, K. Enomoto, K. Suzuki, and A. Yamaguchi, "Basic properties of polylactic acid produced by the direct condensation polymerization of lactic acid," Bulletin of the Chemical Society of Japan, vol. 68, pp. 2125-2131, 1995.

[77] S. I. Moona, C. W. Leeb, I. Taniguchia, M. Miyamotoa, and Y. Kimura, Polymer, vol. 42, p. 5059, 2001.

[78] D. Xiguang, C. Li, Q. Chen, and C. Xuesi, Dongbei Shida Xuebao, Ziran Kexueban, vol. 35, p. 119, 2003.

[79] J. W. Leenslag and A. J. Pennings, "Synthesis of highmolecular-weight poly(L-lactide) initiated with tin 2ethylhexanoate," Die Makromolekulare Chemie, vol. 188, no. 8, pp. 1809-1814, 1987.

[80] H. Yingting, P. Shaoxian, Z. Xipo, and S. Manxing, Suliao Gongye, vol. 37, p. 10, 2009.

[81] Y.-M. Zhang, K.-M. Li, P. Wang, C.-Y. Jiao, and N. Han, "Direct synthesis of poly(l-lactic acid) by melt polycondensation under continuous microwave irradiation," Gaofenzi Cailiao Kexue Yu Gongcheng, vol. 25, no. 10, pp. 27-30, 2009.

[82] D.-K. Yoo and D. Kim, "Production of optically pure poly(lactic acid) from lactic acid," Polymer Bulletin, vol. 63, no. 5, pp. 637-651, 2009.

[83] L. Bo, Zhonggguo Zuzhi Gongcheng Yanjiu Yu Linchuang Kangfu, vol. 12, p. 4594, 2008.

[84] L. Yu-fen, W. Zhao-yang, S. Xiu-mei, M. Zheng-zhou, and Z. Hai-jun, Hecheng Huaxue, vol. 16, p. 166, 2008.

[85] R. Zong-li, L. De-dai, Z. Tian-hong, and L. Zi-qiang, Lanzhou Jiaotong Daxue Xuebao, vol. 27, p. 164, 2008.

[86] X. J. Zhu, Y. Chen, J. S. He, L. Tan, and Y. Wang, "Synthesis of aliphatic-aromatic copolyesters by a melting bulk reaction between poly(butylene terephthalate) and DL-oligo(lactic acid)," High Performance Polymers, vol. 20, no. 2, pp. 166184, 2008.

[87] W. Xun and P. Shaoxian, Suliao Gongye, vol. 35, p. 14, 2007.

[88] T. Kaiguang, H. Guanbao, and Y. Zelin, Hecheng Xianwei Gongye, vol. 30, p. 29, 2007.

[89] S.-I. Moon, I. Taniguchi, M. Miyamoto, Y. Kimura, and C.W. Lee, "Synthesis and properties of high-molecular-weight poly(L-lactic acid) by melt/solid polycondensation under different reaction conditions," High Performance Polymers, vol. 13, no. 2, pp. S189-S196, 2001.

[90] D. C. Tune, “Absorbable bone fixation device," US Patent 4539981, 1985.

[91] D. C. Tune, "Absorbable bone fixation device," US Patent 4550449, 1985.

[92] D. C. Tune, Polymeric Materials: Science and Engineering, vol. 59, p. 383, 1988.

[93] H. Yingting, P. Shaoxian, Z. Xipo, and S. Manxing, Suliao Gongye, vol. 37, p. 10, 2009.

[94] K. Hak Yong, H. Jong Taek, C. Chul Yong, and K. Tae Hyun, Korean Patent KR 96-28593, 1999.

[95] E. G. Kiparisova and B. V. Lebedev, "The thermochemical characteristics of compounds of the polylactone series," Zhurnal Fizicheskoi Khimii, vol. 71, no. 6, pp. 974-979, 1997.

[96] B. Lebedev and A. Yevstropov, "Thermodynamic properties of polylactones," Die Makromolekulare Chemie, vol. 185, no. 6, pp. 1235-1253, 1984. 
[97] B. V. Lebedev, A. A. Evstropov, E. G. Kiparisova, and V. I. Belov, Vysokomolekulyarnye Soedineniya, Seriya A, vol. 20, p. 29, 1978.

[98] B. V. Lebedev, A. A. Evstropov, E. G. Kiparisova, E. B. Lyudvig, and G. S. Sanina, Doklady Akademii Nauk SSSR, vol. 236, p. 669, 1977.

[99] B. Min, S.-H. Kim, S. H. Kim, S. Kwon, H.-J. Kim, and W.-G. Kim, "Free acid effect and NMR study of glycolide," Bulletin of the Korean Chemical Society, vol. 21, no. 6, pp. 635-637, 2000.

[100] K. Hak Yong, K. Myung Seob, H. Jong Tak, Y. Yasuhiro, and K. Kyung Won, Han'guk Somyu Konghakhoechi, vol. 35, p. 38, 1998.

[101] L. Bo, Zhonggguo Zuzhi Gongcheng Yanjiu Yu Linchuang Kangfu, vol. 13, p. 4916, 2009.

[102] W. Jingmei and W. Ruofeng, Hencheng Xianwei Gongye, vol. 29, p. 14, 2006.

[103] H. Cui-qiong, Z. Qing-zhang, and W. Ping, "On some problems in the software development of realtime data acquisition and processing system," Beijing Huagong Daxue Xuebao, Ziran Kexueban, vol. 31, p. 62, 2004.

[104] B. Buchholz, "Process for preparing polyesters based on hydroxycarboxylic acids," US Patent 5302694, 1994.

[105] L. Cotarca, P. Delogu, A. Nardelli, and V. Šunjić, "Bis(trichloromethyl) carbonate in organic synthesis," Synthesis, no. 5, pp. 553-576, 1996.

[106] J. Seppala, J. F. Selin, and T. Su, European Patent 593271, 1993.

[107] J. Seppala, J. F. Selin, and T. Su, "Method for producing lactic acid based polyurethane," US Patent 5380813, 1995.

[108] M. Harkonen, K. Hiltunen, M. Malin, and J. V. Seppala, "Properties and polymerization of biodegradable thermoplastic poly(ester-urethane) ," Journal of Macromolecular Science, Part A, vol. 32, no. 4, pp. 857-862, 1995.

[109] P. V. Bonsignore, "Production of high molecular weight polylactic acid ," US Patent 5470944, 1995.

[110] M. Spinu, "L-Dpolylactide copolymers with controlled morphology," US Patent 5270400, 1993.

[111] A. C. Ibay and L. P. Tenney, "Polymers from hydroxy acids and polycarboxylic acids," US Patent 5206341, 1993.

[112] M. K. Harkonen and J. V. Seppala, Abstracts of the Fourth International Workshop on Biodegradable Polymers J., 1995.

[113] H. Inata and S. Matsumura, "Chain extenders for polyesters. I. addition-type chain extenders reactive with carboxyl end groups of polyesters," Journal of Applied Polymer Science, vol. 30, no. 8, pp. 3325-3337, 1985.

[114] S. M. Aharoni and T. Largman, "Process for preparing graft and block copolymers," US Patent 4417031, 1983.

[115] C. D. Dudgeon, Bis-Orthoesters as Polymer Intermediates, M.S. thesis, University of Massachusetts, 1976.

[116] S. M. Aharoni and D. Masilamani, "Process for preparing extended chain polyesters and block or graft copolyesters," US Patent 4568720, 1986.

[117] S. M. Aharoni, C. E. Forbes, W. B. Hammond et al., "Hightemperature reactions of hydroxyl and carboxyl pet chain end groups in the presence of aromatic phosphite," Journal of Polymer Science Part A, vol. 24, no. 6, pp. 1281-1296, 1986.

[118] S. Gogolewski and A. J. Pennings, "Biodegradable materials of polylactides, 4. Porous biomedical materials based on mixtures of polylactides and polyurethanes," Die Makromolekulare Chemie, Rapid Communications, vol. 3, no. 12, pp. 839-845, 1982.
[119] B. Eling, S. Gogolewski, and A. J. Pennings, "Biodegradable materials of poly(l-lactic acid): 1. Melt-spun and solutionspun fibres," Polymer, vol. 23, no. 11, pp. 1587-1593, 1982.

[120] A. G. Pinkus and R. Subramanyam, "New high-yield, onestep synthesis of polyglycolide from haloacetic acids," Journal of Polymer Science Part A, vol. 22, no. 5, pp. 1131-1140, 1984.

[121] S. Yuxiang, Z. Jin, and Y. Lubing, Huagong Shikan, vol. 14, p. $50,2000$.

[122] T. Masuda, K. Kagami, K. Murata, A. Matsuda, and Y. Takami, Nippon Kagaku Kaishi, vol. 2, p. 257, 1982.

[123] S. Kobayashi and H. Uyama, "In vitro biosynthesis of polyesters," in Biopolyesters, W. Babel and A. Steinbuchel, Eds., vol. 71 of Advances in Biochemical Engineering/Biotechnology, pp. 241-262, Springer, Heidelberg, Germany, 2001.

[124] H. Uyama and S. Kobayashi, "Enzymatic ring-opening polymerization of lactones catalyzed by lipase," Chemistry Letters, vol. 7, pp. 1149-1150, 1993.

[125] D. Knani, A. L. Gutman, and D. H. Kohn, "Enzymatic polyesterification in organic media. Enzyme-catalyzed synthesis of linear polyesters. I. Condensation polymerization of linear hydroxyesters. II. Ring-opening polymerization of $\varepsilon$ caprolactone," Journal of Polymer Science Part A, vol. 31, no. 5, pp. 1221-1232, 1993.

[126] R. T. MacDonald, S. K. Pulapura, Y. Y. Svirkin et al., "Enzyme-catalyzed $\varepsilon$-caprolactone ring-opening polymerization," Macromolecules, vol. 28, no. 1, pp. 73-78, 1995.

[127] G. A. R. Nobes, R. J. Kazlauskas, and R. H. Marchessault, "Lipase-catalyzed ring-opening polymerization of lactones: a novel route to poly(hydroxyalkanoate)s," Macromolecules, vol. 29, no. 14, pp. 4829-4833, 1996.

[128] S. Matsumura, K. Mabuchi, and K. Toshima, "Lipasecatalyzed ring-opening polymerization of lactide," Macromolecular Rapid Communications, vol. 18, no. 6, pp. 477-482, 1997.

[129] S. Matsumura, H. Beppu, K. Tsukada, and K. Toshima, "Enzyme-catalyzed ring-opening polymerization of $\beta$ propiolactone," Biotechnology Letters, vol. 18, no. 9, pp. 1041-1046, 1996.

[130] S. Matsumura, Y. Suzuki, K. Tsukada, K. Toshima, Y. Doi, and K.-I. Kasuya, "Lipase-catalyzed ring-opening polymerization of $\beta$-butyrolactone to the cyclic and linear poly(3hydroxybutyrate)," Macromolecules, vol. 31, no. 19, pp. 64446449, 1998

[131] Y. Osanai, K. Toshima, and S. Matsumura, "Lipase-catalyzed reaction of molecularly pure linear and cyclic poly(3hydroxybutanoate)s: evidence of cyclic polymer formation," Chemistry Letters, no. 5, pp. 576-577, 2000.

[132] H. Nishida, M. Yamashita, M. Nagashima, T. Endo, and Y. Tokiwa, "Synthesis of metal-free poly(1,4-dioxan-2-one) by enzyme-catalyzed ring-opening polymerization," Journal of Polymer Science Part A, vol. 38, no. 9, pp. 1560-1567, 2000.

[133] H. Uyama, S. Suda, H. Kikuchi, and S. Kobayashi, "Extremely efficient catalysis of immobilized lipase in ring-opening polymerization of lactones," Chemistry Letters, vol. 26, no. 11, pp. 1109-1110, 1997.

[134] A. Córdova, T. Iversen, K. Hult, and M. Martinelle, "Lipasecatalysed formation of macrocycles by ring-opening polymerisation of $\varepsilon$-caprolactone," Polymer, vol. 39, no. 25, pp. 6519-6524, 1998.

[135] H. Uyama, K. Takeya, N. Hoshi, and S. Kobayashi, "Lipasecatalyzed ring-opening polymerization of 12-dodecanolide," Macromolecules, vol. 28, no. 21, pp. 7046-7050, 1995. 
[136] A. Kumar, B. Kalra, A. Dekhterman, and R. A. Gross, "Efficient ring-opening polymerization and copolymerization of $\varepsilon$-caprolactone and $\omega$-pentadecalactone catalyzed by Candida antartica lipase B," Macromolecules, vol. 33, no. 17, pp. 6303-6309, 2000.

[137] S. Kobayashi, H. Uyama, S. Namekawa, and H. Hayakawa, "Enzymatic ring-opening polymerization and copolymerization of 8-octanolide by lipase catalyst," Macromolecules, vol. 31, no. 17, pp. 5655-5659, 1998.

[138] G. Odian, Principles of Polymerization, Wiley-Interscience, Hoboken, NJ, USA, 4th edition, 2004.

[139] B. M. Trost, "The atom economy-a search for synthetic efficiency," Science, vol. 254, no. 5037, pp. 1471-1477, 1991.

[140] L. J. Gold, Chemical Physics, vol. 28, p. 91, 1958.

[141] S. Penczek, A. Duda, R. Szymanski, and T. Biela, "What we have learned in general from cyclic esters polymerization," Macromolecular Symposia, vol. 153, pp. 1-15, 2000.

[142] R. Szymanski, "Molecular weight distribution in living polymerization proceeding with reshuffling of polymer segments due to chain transfer to polymer with chain scission, 1: determination of $\mathrm{kp} / \mathrm{ktr}$ ratio from $\mathrm{DPw} / \mathrm{DPn}$ data. Ideal reproduction of polymer chain activities," Macromolecular Theory and Simulations, vol. 7, no. 1, pp. 27-39, 1998.

[143] R. A. Gross, A. Kumar, and B. Kalra, "Polymer synthesis by in vitro enzyme catalysis," Chemical Reviews, vol. 101, no. 7, pp. 2097-2124, 2001.

[144] S. Kobayashi, "Enzymatic ring-opening polymerization of lactones by lipase catalyst: mechanistic aspects," Macromolecular Symposia, vol. 240, pp. 178-185, 2006.

[145] K. Chujo, H. Kobayashi, J. Suzuki, S. Tokuhara, and M. Tanabe, "Ring-opening polymerization of glycolide," Die Makromolekulare Chemie, vol. 100, no. 1, pp. 262-266, 1967.

[146] C. E. Lowe, "Preparation of high molecular weight polyhydroxyacetic ester," US Patent 2668162, 1954.

[147] W. Dittrich and R. C. Schulz, "Kinetik und Mechanismus der ringöffnenden Polymerisation von L(-)-Lactid," Die Angewandte Die Makromolekulare Chemie, vol. 15, no. 1, pp. 109-126, 1971.

[148] H. R. Kricheldorf, J. M. Jonte, and R. Dunsing, "Polylactones, 7. The mechanism of cationic polymerization of $\beta$-propiolactone and $\varepsilon$-caprolactone," Die Makromolekulare Chemie, vol. 187, no. 4, pp. 771-785, 1986.

[149] H. R. Kricheldorf, R. Dunsing, and A. Serra, "Polylactones. 10. Cationic polymerization of $\delta$-valerolactone by means of alkylating reagents," Macromolecules, vol. 20, no. 9, pp. 2050 2057, 1987.

[150] H. R. Kricheldorf and R. Dunsing, "Polylactones, 8. Mechanism of the cationic polymerization of L,L-dilactide," Die Makromolekulare Chemie, vol. 187, no. 7, pp. 1611-1625, 1986.

[151] H. R. Kricheldorf and I. Kreiser, "Polylactones, 11. Cationic copolymerization of glycolide with L,L-dilactide," Die Makromolekulare Chemie, vol. 188, no. 8, pp. 1861-1873, 1987.

[152] D. Bourissou, B. Martin-Vaca, A. Dumitrescu, M. Graullier, and F. Lacombe, "Controlled cationic polymerization of lactide," Macromolecules, vol. 38, no. 24, pp. 9993-9998, 2005.

[153] M. Baśko and P. Kubisa, "Cationic copolymerization of $\mathcal{E}$-caprolactone and L,L-lactide by an activated monomer mechanism," Journal of Polymer Science Part A, vol. 44, no. 24, pp. 7071-7081, 2006.
[154] B. Atthoff, J. Hilborn, and T. Bowden, PMSE Preprints, vol. 88, p. 369, 2003.

[155] T. Bowden, J. G. Hilborn, and N. Eriksson, PMSE Preprints, vol. 88, p. 535, 2003.

[156] Y. Shibasaki, H. Sanada, M. Yokoi, F. Sanda, and T. Endo, "Activated monomer cationic polymerization of lactones and the application to well-defined block copolymer synthesis with seven-membered cyclic carbonate," Macromolecules, vol. 33, no. 12, pp. 4316-4320, 2000.

[157] M. S. Kim, K. S. Seo, G. Khang, and H. B. Lee, "Ring-opening polymerization of $\mathcal{\varepsilon}$-caprolactone by poly(ethylene glycol) by an activated monomer mechanism," Macromolecular Rapid Communications, vol. 26, no. 8, pp. 643-648, 2005.

[158] X. Lou, C. Detrembleur, and R. Jérôme, "Living cationic polymerization of $\delta$-valerolactone and synthesis of high molecular weight homopolymer and asymmetric telechelic and block copolymer," Macromolecules, vol. 35, no. 4, pp. 1190-1195, 2002.

[159] J. Casas, P. V. Persson, T. Iversen, and A. Córdova, "Direct organocatalytic ring-opening polymerizations of lactones," Advanced Synthesis and Catalysis, vol. 346, no. 9-10, pp. 1087-1089, 2004.

[160] P. V. Persson, J. Schröder, K. Wickholm, E. Hedenström, and T. Iversen, "Selective organocatalytic ring-opening polymerization: a versatile route to carbohydrate-functionalized poly( $\in$-caprolactones)," Macromolecules, vol. 37, no. 16, pp. 5889-5893, 2004.

[161] P. V. Persson, J. Casas, T. Iversen, and A. Córdova, "Direct organocatalytic chemoselective synthesis of a dendrimer-like star polyester," Macromolecules, vol. 39, no. 8, pp. 2819-2822, 2006.

[162] F. Sanda, H. Sanada, Y. Shibasaki, and T. Endo, "Star polymer synthesis from $\varepsilon$-caprolactone utilizing polyol/protonic acid initiator," Macromolecules, vol. 35, no. 3, pp. 680-683, 2002.

[163] F. Zeng, H. Lee, M. Chidiac, and C. Allen, "Synthesis and characterization of six-arm star poly ( $\delta$-valerolactone)-blockmethoxy poly(ethylene glycol) copolymers," Biomacromolecules, vol. 6, no. 4, pp. 2140-2149, 2005.

[164] J. Y. Liu and L. J. Liu, "Ring-opening polymerization of $\varepsilon$-caprolactone initiated by natural amino acids," Macromolecules, vol. 37, no. 8, pp. 2674-2676, 2004.

[165] B. C. Wilson and C. W. Jones, "A recoverable, metal-free catalyst for the green polymerization of $\varepsilon$-caprolactone," Macromolecules, vol. 37, no. 26, pp. 9709-9714, 2004.

[166] Z. Jedliński, P. Kurcok, and M. Kowalczuk, "Polymerization of $\beta$-lactones initiated by potassium solutions," Macromolecules, vol. 18, no. 12, pp. 2679-2683, 1985.

[167] Z. Jedliński and M. Kowalczuk, "Nature of the active centers and the propagation mechanism of the polymerization of $\beta$-propiolactones initiated by potassium anions," Macromolecules, vol. 22, no. 8, pp. 3242-3244, 1989.

[168] Z. Jedliński, M. Kowalczuk, and P. Kurcok, "What is the real mechanism of anionic polymerization of $\beta$-lactones by potassium alkoxides? A critical approach," Macromolecules, vol. 24, no. 5, pp. 1218-1219, 1991.

[169] Z. Jedlinski, P. Kurock, W. Walach, H. Janeezek, and I. Radecka, "Polymerization of lactones, 17. Synthesis of ethylene glycol-L-lactide block copolymers," Die Makromolekulare Chemie, vol. 194, no. 6, pp. 1681-1689, 1993.

[170] P. Kurock, S. Penczek, J. Franck, and Z. Jedlinski, "Anionic polymerization of lactones. 14 . Anionic block copolymerization of $\delta$-valerolactone and L-lactide initiated with potassium methoxide," Macromolecules, vol. 25, no. 9, pp. 22852289, 1992. 
[171] P. Kurcok, M. Kowalczuk, K. Hennek, and Z. Jedliński, "Anionic polymerization of $\beta$-lactones initiated with alkalimetal alkoxides: reinvestigation of the polymerization mechanism," Macromolecules, vol. 25, no. 7, pp. 2017-2020, 1992.

[172] A. P. Dove, Chemical Communications, vol. 6446, 2008.

[173] O. Dechy-Cabaret, B. Martin-Vaca, and D. Bourissou, "Controlled ring-opening polymerization of lactide and glycolide," Chemical Reviews, vol. 104, no. 12, pp. 6147-6176, 2004.

[174] J. E. Kasperczyk, "Microstructure analysis of poly(lactic acid) obtained by lithium tert-butoxide as initiator," Macromolecules, vol. 28, no. 11, pp. 3937-3939, 1995.

[175] M. Bero, P. Dobrzynski, and J. Kasperczyk, Journal of Polymer Science Part A, vol. 73, p. 37, 1993.

[176] M. Bero and J. Ksperczyk, Polymer, vol. 41, p. 391, 2000.

[177] F. Hild, P. Haquette, L. Brelot, and S. Dagorne, "Synthesis and structural characterization of well-defined anionic aluminium alkoxide complexes supported by NON-type diamido ether tridentate ligands and their use for the controlled ROP of lactide," Dalton Transactions, vol. 39, no. 2, pp. 533-540, 2010.

[178] A. Kowalski, A. Duda, and S. Penczek, "Kinetics and mechanism of cyclic esters polymerization initiated with tin(II) octoate, 1: polymerization of $\varepsilon$-caprolactone," Macromolecular Rapid Communications, vol. 19, no. 11, pp. 567-572, 1998.

[179] H. R. Kricheldorf, I. Kreiser-Saunders, and C. Boettcher, "Polylactones: 31. Sn(II)octoate-initiated polymerization of L-lactide: a mechanistic study," Polymer, vol. 36, no. 6, pp. 1253-1259, 1995.

[180] P. J. A. In't Veld, E. M. Velner, P. van de Witte, J. Hamhuis, P. J. Dijkstra, and J. Feijen, "Melt block copolymerization of $\varepsilon$-caprolactone and L-lactide," Journal of Polymer Science Part A, vol. 35, no. 2, pp. 219-226, 1997.

[181] Y. J. Du, A. J. Nijenhous, C. Bastiassen, and P. J. Lemstra, Journal of Macromolecular Science Part A, vol. 32, p. 1061, 1995.

[182] G. Schwach, J. Coudane, R. Engel, and M. Vert, "More about the polymerization of lactides in the presence of stannous octoate," Journal of Polymer Science Part A, vol. 35, no. 16, pp. 3431-3440, 1997.

[183] X. Zhang, D. A. Macdonald, M. F. A. Goosen, and K. B. Mcauley, "Mechanism of lactide polymerization in the presence of stannous octoate: the effect of hydroxy and carboxylic acid substances," Journal of Polymer Science Part A, vol. 32, no. 15, pp. 2965-2970, 1994.

[184] PH. Dubois, N. Ropson, R. Jérôme, and PH. Teyssié, "Macromolecular engineering of polylactones and polylactides. 19. Kinetics of ring-opening polymerization of $\varepsilon$ caprolactone initiated with functional aluminum alkoxides," Macromolecules, vol. 29, no. 6, pp. 1965-1975, 1996.

[185] J. Libiszowski, A. Kowalski, A. Duda, and S. Penczek, "Kinetics and mechanism of cyclic esters polymerization initiated with covalent metal carboxylates, 5: end-group studies in the model $\varepsilon$-caprolactone and L,L-dilactide/tin(II) and zinc octoate/butyl alcohol systems," Macromolecular Chemistry and Physics, vol. 203, no. 10-11, pp. 1694-1701, 2002.

[186] H. R. Kricheldorf, I. Kreiser-Saunders, and A. Stricker, "Polylactones 48 . $\mathrm{SnOct}_{2}$-initiated polymerizations of lactide: a mechanistic study," Macromolecules, vol. 33, no. 3, pp. 702$709,2000$.

[187] M. Bero and J. Kasperczyk, "Coordination polymerization of lactides, 5: influence of lactide structure on the transesterification processes in the copolymerization with $\varepsilon$ caprolactone," Macromolecular Chemistry and Physics, vol. 197, no. 10, pp. 3251-3258, 1996.
[188] X. Liu, K. Li, X. Feng, and Y. Cao, "Preparation of propargylterminated polylactide by the bulk ring-opening polymerization," Journal of Macromolecular Science Part A, vol. 46, no. 10, pp. 937-942, 2009.

[189] C. Gordin, C. Delaite, H. Medlej, J.-L. Delphine, K. Hariri, and M. Rusu, "Synthesis of ABC miktoarm star block copolymers from a new heterotrifunctional initiator by combination of ATRP and ROP," Polymer Bulletin, vol. 63, no. 6, p. 789, 2009.

[190] J. Yu-shun, S. Yu-wei, G. Wen-li, and L. Shu-xin, Huaxue Yu Nianhe, vol. 30, p. 35, 2008.

[191] M. Jalabert, C. Fraschini, and R. E. Prud'Homme, "Synthesis and characterization of poly(L-lactide)s and poly(D-lactide)s of controlled molecular weight," Journal of Polymer Science Part A, vol. 45, no. 10, pp. 1944-1955, 2007.

[192] W. Hai-yan, L. Feng, L. Shi-piao, and C. Xiao-huan, Huaxue Yu Shengwu Gongcheng, vol. 22, p. 29, 2005.

[193] S. Jing, W. Peng, Z. Ke, T. Liu-yi, Z. Tong, and Z. Bao-xiu, Gaoxiao Huaxue Gongcheng Xuebao, vol. 19, p. 498, 2005.

[194] F. Yang, L. Liu, Z. Wei, Y. Zhao, C. Zhang, and M. Qi, "Effect of chain transfer agent to synthesis of poly(D,L-)lactides," Hecheng Shuzhi Ji Suliao, vol. 22, no. 2, pp. 38-41, 2005.

[195] Z. Ke, W. Peng, L. Wen-ke, and S. Jing, Gaofenzi Cailiao Kexue Yu Gongcheng, vol. 20, p. 46, 2004.

[196] J. Ma, H. Cao, Y. Li, and Y. Li, "Synthesis and characterization of poly(DL-lactide)-grafted gelatins as bioabsorbable amphiphilic polymers," Journal of Biomaterials Science, Polymer Edition, vol. 13, no. 1, pp. 67-80, 2002.

[197] Z. Yao-ming, M. Hang-zhen, C. Jun-wu, and G. Qian-fei, Huanan Ligong Daxue Xuebao, Ziran Kexueban, vol. 28, p. 53, 2000.

[198] D. Chen and B. Sun, "New tissue engineering material copolymers of derivatives of cellulose and lactide: their synthesis and characterization," Materials Science and Engineering $C$, vol. 11, no. 1, pp. 57-60, 2000.

[199] Z. Guodong, F. Xinde, and G. Zhongwei, Gaofenzi Xuebao, vol. 4, p. 509, 1998.

[200] Z. Wanxi, Suliao Gongye, vol. 34, p. 1, 2006.

[201] M. Yasushi, Shokubai, vol. 42, p. 228, 2000.

[202] A. Kafrawy and S. W. Shalaby, "A new synthesis of 1,5dioxepan-2-one," Journal of Polymer Science Part A, vol. 25, no. 9, pp. 2629-2630, 1987.

[203] A. J. Neijenhuis, D. W. Grijmpa, and A. J. Pennings, "Lewis acid catalyzed polymerization of L-lactide. Kinetics and mechanism of the bulk polymerization," Macromolecules, vol. 25, no. 24, pp. 6419-6424, 1992.

[204] G. Rafler and J. Dahlmann, "Biodegradable polymers. 6th comm. Polymerization of $\varepsilon$-caprolactone," Acta Polymerica, vol. 43, no. 2, pp. 91-95, 1992.

[205] J. W. Leenslag and A. J. Pennings, "Synthesis of highmolecular-weight poly(L-lactide) initiated with tin 2ethylhexanoate," Die Makromolekulare Chemie, vol. 188, no. 8, pp. 1809-1814, 1987.

[206] Y. J. Du, P. J. Lemstra, A. J. Neijenhuis, H. A. M. Vanaert, and C. Bastiaannsen, "ABA type copolymers of lactide with poly(ethylene glycol). Kinetic, mechanistic, and model studies," Macromolecules, vol. 28, no. 7, pp. 2124-2132, 1995.

[207] A. Duda, S. Penczek, A. Kowalski, and J. Libiszowski, "Polymerizations of $\varepsilon$-caprolactone and L,L-dilactide initiated with stannous octoate and stannous butoxide-a comparison," Macromolecular Symposia, vol. 153, pp. 41-53, 2000.

[208] A. Kowalski, A. Duda, and S. Penczek, "Mechanism of cyclic ester polymerization initiated with Tin(II) octoate. 2. 1 
macromolecules fitted with Tin(II) alkoxide species observed directly in MALDI-TOF spectra," Macromolecules, vol. 33, no. 3, pp. 689-695, 2000.

[209] A. Kowalski, A. Duda, and S. Penczek, "Kinetics and mechanism of cyclic esters polymerization initiated with tin(II) octoate. 3. Polymerization of L,L-dilactide," Macromolecules, vol. 33, no. 20, pp. 7359-7370, 2000.

[210] M. Ryner, K. Stridsberg, A.-C. Albertsson, H. von Schenck, and M. Svensson, "Mechanism of ring-opening polymerization of 1,5-dioxepan-2-one and L-lactide with stannous 2ethylhexanoate. A theoretical study," Macromolecules, vol. 34, no. 12, pp. 3877-3881, 2001.

[211] A. Kowalski, J. Libiszowski, A. Duda, and S. Penczek, "Polymerization of 1, 1-dilactide initiated by tin(ii) butoxide," Macromolecules, vol. 33, no. 6, pp. 1964-1971, 2000.

[212] H. R. Kricheldorf and I. Kreiser-Saunders, "Polylactones 49: Bu4Sn-initiated polymerizations of $\varepsilon$-caprolactone," Polymer, vol. 41, no. 11, pp. 3957-3963, 2000.

[213] H. R. Kricheldorf, M. V. Sumbél, and I. Kreiser-Saunders, "Polylactones. 20. Polymerization of $\in$-caprolactone with tributyltin derivatives: a mechanistic study," Macromolecules, vol. 24, no. 8, pp. 1944-1949, 1991.

[214] H. R. Kricheldorf, C. Boettcher, and K.-U. Tönnes, "Polylactones: 23. Polymerization of racemic and meso d,l-lactide with various organotin catalysts-stereochemical aspects," Polymer, vol. 33, no. 13, pp. 2817-2824, 1992.

[215] K. Stridsberg and A.-C. Albertsson, "Ring-opening polymerization of 1,5-dioxepan-2-one initiated by a cyclic tinalkoxide initiator in different solvents," Journal of Polymer Science Part A, vol. 37, no. 16, pp. 3407-3417, 1999.

[216] H. R. Kricheldorf and S. Eggerstedt, "Macrocycles 2: living macrocyclic polymerization of $\varepsilon$-caprolactone with 2,2 dibutyl-2-stanna-1,3-dioxepane as initiator," Macromolecular Chemistry and Physics, vol. 199, no. 2, pp. 283-290, 1998.

[217] H. Von Schenk, M. Ryner, A.-C. Albertsson, and M. Svensson, Macromolecules, vol. 35, p. 1536, 2002.

[218] K. Stridsberg, M. Ryner, and A.-C. Albertsson, "Dihydroxyterminated poly(L-lactide) obtained by controlled ringopening polymerization: investigation of the polymerization mechanism," Macromolecules, vol. 33, no. 8, pp. 2862-2869, 2000.

[219] K. Stridsberg and A.-C. Albertsson, "Controlled ringopening polymerization of L-lactide and 1,5-dioxepan-2-one forming a triblock copolymer," Journal of Polymer Science Part A, vol. 38, no. 10, pp. 1774-1784, 2000.

[220] C.-H. Zhang and F. Liu, "Synthesis of molecular weight controllable polylactide by using organocatalyst," Gongneng Cailiao, vol. 40, no. 9, pp. 1502-1505, 2009.

[221] A. Löfgren, A.-C. Albertsson, PH. Dubois, R. Jérôme, and PH. Teyssié, "Synthesis and characterization of biodegrable homopolymers and block copolymers based on 1,5dioxepan-2-one," Macromolecules, vol. 27, no. 20, pp. 5556$5562,1994$.

[222] N. Rapson, A.-C. Albertsson, A.-C. Dubois, R. Jerome, and P. Teyese, Macromolecules, vol. 28, p. 3027, 1995.

[223] A. Löfgren and A.-C. Albertsson, "Synthesis and characterization of high molecular weight poly(1,5-dioxepan-2-one) with narrow molecular weight distribution," Polymer, vol. 36, no. 19, pp. 3753-3759, 1995.

[224] S. Lundmark, M. Sjoling, and A. C. Albertsson, "Polymerization of oxepan-2,7-dione in solution and synthesis of block copolymers of oxepan-2,7-dione and 2-oxepanone," Journal of Macromolecular Science, Part A, vol. 28, no. 1, pp. 15-29, 1991.
[225] A. Lofgren, R. Renstad, and A.-C. Albertsson, "Synthesis and characterization of a new degradable thermoplastic elastomer based on 1,5-dioxepan-2-one and $\varepsilon$-caprolactone," Journal of Applied Polymer Science, vol. 55, no. 11, pp. 1589$1600,1995$.

[226] T. Ouhadi, C. Stevens, and P. Teyssié, "Mechanism of $\varepsilon$ caprolactone polymerization by aluminum alkoxides," Die Makromolekulare Chemie. Supplement, vol. 1, no. S19751, pp. 191-201, 1975.

[227] A. Kowalski, A. Duda, and S. Penczek, "Polymerization of L,L-lactide initiated by aluminum isopropoxide trimer or tetramer," Macromolecules, vol. 31, no. 7, pp. 2114-2122, 1998.

[228] M. Bero, J. Kasperezyk, and Z. Jedlinski, "Coordination polymerization of lactides, 1. Structure determination of obtained polymers," Die Makromolekulare Chemie, vol. 191, no. 10, pp. 2287-2296, 1990.

[229] P. Dubois, C. Jacobs, R. Jérôme, and PH. Teyssié, "Macromolecular engineering of polylactones and polylactides. 4 . Mechanism and kinetics of lactide homopolymerization by aluminum isopropoxide," Macromolecules, vol. 24, no. 9, pp. 2266-2270, 1991.

[230] A. Duda, Z. Florjanezyk, A. Hofman, S. Slomkowski, and S. Penezek, Macromolecules, vol. 23, p. 1640, 1990.

[231] G. Montaudo, M. S. Montaudo, C. Puglisi et al., Macromolecules, vol. 29, p. 1399, 1996.

[232] A. Duda and S. Penezek, Macromolecular Symposia, vol. 47, p. 127, 1991.

[233] A. Duda, "Polymerization of $\varepsilon$-caprolactone initiated by aluminum isopropoxide carried out in the presence of alcohols and diols. Kinetics and mechanism," Macromolecules, vol. 29, no. 5, pp. 1399-1406, 1996.

[234] A. Duda and S. Penezek, Macromolecules, vol. 27, p. 1867, 1994.

[235] A. Kowalski, A. Duda, and S. Penczek, "Polymerization of L,L-lactide initiated by aluminum isopropoxide trimer or tetramer," Macromolecules, vol. 31, no. 7, pp. 2114-2122, 1998.

[236] S. Inoue, "From living to 'immortal' polymerization," Journal of Macromolecular Science, Part A, vol. A25, no. 5-7, pp. 571$582,1988$.

[237] K. Shimasaki, T. Aida, and S. Inoue, "Living polymerization of $\delta$-valerolactone with aluminum porphyrin. Trimolecular mechanism by the participation of two aluminum porphyrin molecules," Macromolecules, vol. 20, no. 12, pp. 3076-3080, 1987.

[238] S. J. Mclain and N. F. Drysdale, "Yttrium and rare earth compounds catalyzed lactone polymerization," US Patent 5028667, 1991.

[239] S. J. Mclain and N. F. Drysdale, Polymer Preprints, American Chemical Society, vol. 33, p. 463, 1992.

[240] W. Stevels, P. J. Dijkstra, and Feijen, Trends in Polymer Science, vol. 5, p. 300, 1997.

[241] W. M. Stevels, M. J. K. Ankoné, P. J. Dijkstra, and J. Feijen, "Kinetics and mechanism of L-lactide polymerization using two different yttrium alkoxides as initiators," Macromolecules, vol. 29, no. 19, pp. 6132-6138, 1996.

[242] Z. Q. Shen, Y. Q. Shen, J. Q. Sun, F. Y. Zhang, and Y. F. Zhang, Chinese Science Bulletin, vol. 39, no. 5, p. 1096, 1994.

[243] Z. Q. Shen, Y. Q. Shen, J. Q. Sun, F. Y. Zhang, and Y. F. Zhang, Polymer, vol. 27, p. 59, 1995.

[244] W. M. Stevels, M. J. K. Ankoné, P. J. Dijkstra, and J. Feijen, "Kinetics and mechanism of $\in$-caprolactone polymerization 
using yttrium alkoxides as initiators," Macromolecules, vol. 29, no. 26, pp. 8296-8303, 1996.

[245] W. M. Stevels, M. J. K. Ankone, P. J. Dijkstra, and J. Feijen, "Versatile and highly efficient catalyst system for the preparation of polyesters based on lanthanide tris(2,6-ditert-butylphenolate)s and various alcohols," Macromolecules, vol. 29, no. 9, pp. 3332-3333, 1996.

[246] S. Agrawal, C. Mast, K. Dehnicke, and A. Grenier, "Rare earth metal initiated ring-opening polymerization of lactones," Macromolecular Rapid Communication, vol. 21, no. 5, pp. 195-212, 2000.

[247] Y. Kim and J. G. Verkade, "Novel titanatranes with different ring sizes: syntheses, structures, and lactide polymerization catalytic capabilities," Organometallics, vol. 21, no. 12, pp. 2395-2399, 2002.

[248] Y. Kim, P. N. Kapoor, and J. G. Verkade, " $(\mathrm{RO})_{2} 2 \mathrm{Ta}[\operatorname{tris}(2-$ oxy-3,5-dimethylbenzyl)amine]: structure and lactide polymerization activities," Inorganic Chemistry, vol. 41, no. 18, pp. 4834-4838, 2002.

[249] Y. Kim and J. G. Verkade, "A tetrameric titanium alkoxide as a lactide polymerization catalyst," Macromolecular Rapid Communications, vol. 23, no. 15, pp. 917-921, 2002.

[250] Y. Takashima, Y. Nakayama, K. Watanabe et al., "Polymerizations of cyclic esters catalyzed by titanium complexes having chalcogen-bridged chelating diaryloxo ligands," Macromolecules, vol. 35, no. 20, pp. 7538-7544, 2002.

[251] D. A. Culkin, W. Jeong, S. Csihony et al., "Zwitterionic polymerization of lactide to cyclic poly(lactide) by using Nheterocyclic carbene organocatalysts," Angewandte Chemie International Edition, vol. 46, no. 15, pp. 2627-2630, 2007.

[252] B. Yanbin, H. Xiaqin, and L. Ziqiang, Gaofenzi Tongbao, vol. 3, p. 46, 2006.

[253] G. Schwach, J. Coudane, R. Engel, and M. Vert, "Stannous octoate-versus zinc-initiated polymerization of racemic lactide-effects on configurational structures," Polymer Bulletin, vol. 32, no. 5-6, pp. 617-623, 1994.

[254] G. Schwach, J. Coudane, R. Engel, and M. Vert, "Stannous octoate-versus zinc-initiated polymerization of racemic lactide-effects on configurational structures," Polymer Bulletin, vol. 32, no. 5-6, pp. 617-623, 1994.

[255] M. Vert, G. Schwach, and J. Coudane, "Present and future of PLA polymers," Journal of Macromolecular Science, Part A, vol. 32, no. 4, pp. 787-796, 1995.

[256] G. Schwach, J. Coudane, R. Engel, and M. Vert, "Ring opening polymerization of D,L-Lactide in the presence of zinc metal and zinc lactate," Polymer International, vol. 46, no. 3, pp. 177-182, 1998.

[257] G. Schwach and M. Vert, "In vitro and in vivo degradation of lactic acid-based interference screws used in cruciate ligament reconstruction," International Journal of Biological Macromolecules, vol. 25, no. 1-3, pp. 283-291, 1999.

[258] G. Schwach, J. Coudane, R. Engel, and M. Vert, "Influence of polymerization conditions on the hydrolytic degradation of poly(DL-lactide) polymerized in the presence of stannous octoate or zinc-metal," Biomaterials, vol. 23, no. 4, pp. 9931002, 2002.

[259] M. Vert, G. Schwach, R. Engel, and J. Coudane, "Something new in the field of PLA/GA bioresorbable polymers?" Journal of Controlled Release, vol. 53, no. 1-3, pp. 85-92, 1998.

[260] H. R. Kricheldorf and D.-O. Damrau, "Polylactones, 37: polymerizations of L-lactide initiated with $\mathrm{Zn}$ (II) L-lactate and other resorbable Zn salts," Macromolecular Chemistry and Physics, vol. 198, no. 6, pp. 1753-1766, 1997.
[261] H. R. Kricheldorf, D.-O. Damru, and I. Krieser-Saunders, Macromolecular Chemistry and Physics, vol. 199, p. 1081, 1998.

[262] H. R. Kricheldorf and D.-O. Damru, "Polylactones, 42. Zn L-lactate-catalyzed polymerizations of 1,4-dioxan-2-one," Macromolecular Chemistry and Physics, vol. 199, no. 6, pp. 1089-1097, 1998.

[263] P. Dobrzyński, J. Kasperczyk, and M. Bero, "Application of calcium acetylacetonate to the polymerization of glycolide and copolymerization of glycolide with $\varepsilon$-caprolactone and L-lactide," Macromolecules, vol. 32, no. 14, pp. 4735-4737, 1999.

[264] Z. Zhong, S. Schneiderbauer, P. J. Dijkstra, M. Westerhausen, and J. Feijen, "Fast and living ring-opening polymerization of L-lactide initiated with in-situ-generated calcium alkoxides," Journal of Polymers and the Environment, vol. 9, no. 1, pp. 3138, 2001.

[265] H. R. Kricheldorf, T. Mang, and J. M. Jonté, "Polylactones. 1. Copolymerization of glycolide and $\varepsilon$-caprolactone," Macromolecules, vol. 17, no. 10, pp. 2173-2181, 1984.

[266] A. Finna and A.-C. Albertsson, "New functionalized polyesters to achieve controlled architectures," Journal of Polymer Science Part A, vol. 42, no. 3, pp. 444-452, 2003. 

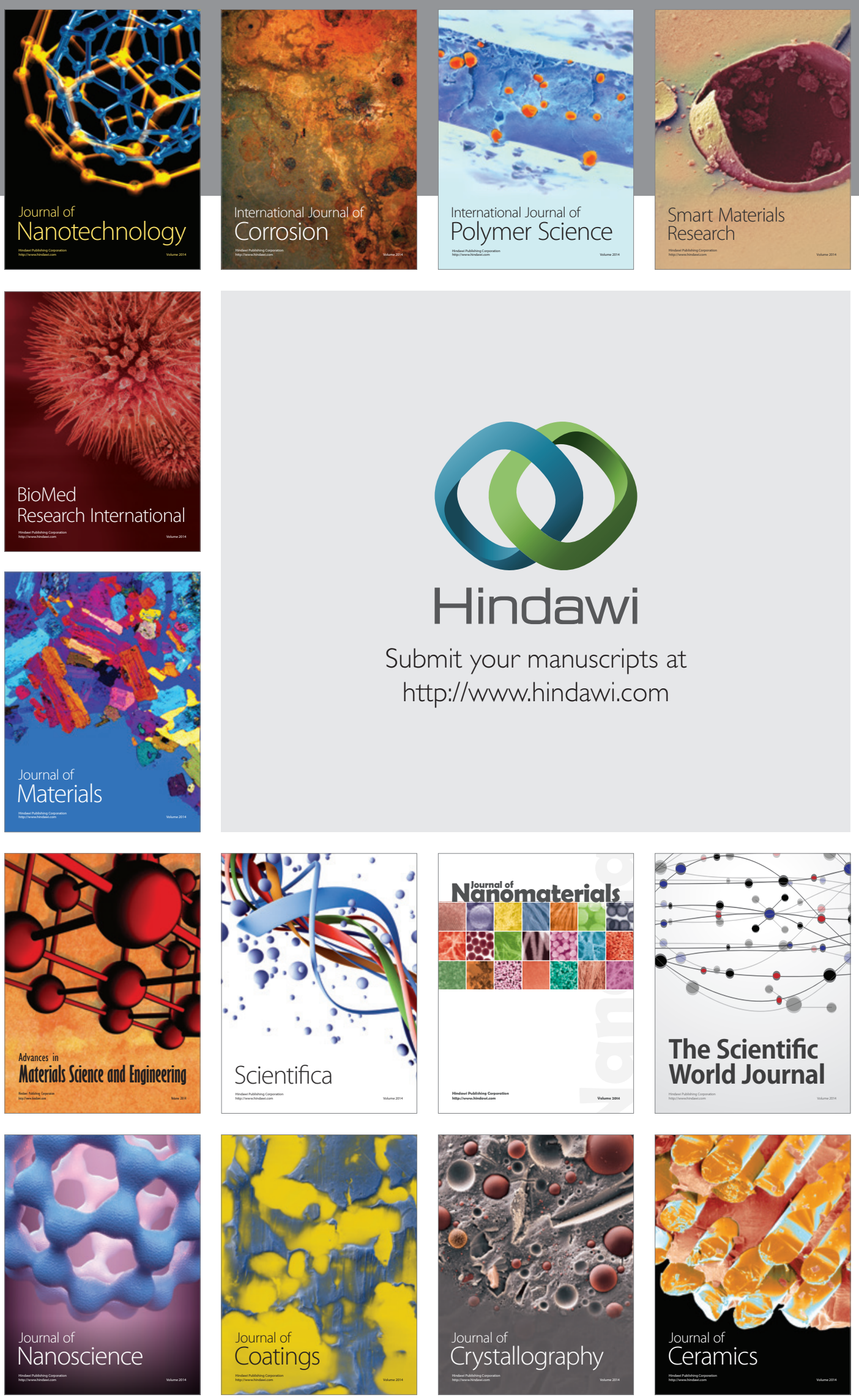

The Scientific World Journal

Submit your manuscripts at

http://www.hindawi.com

\section{World Journal}

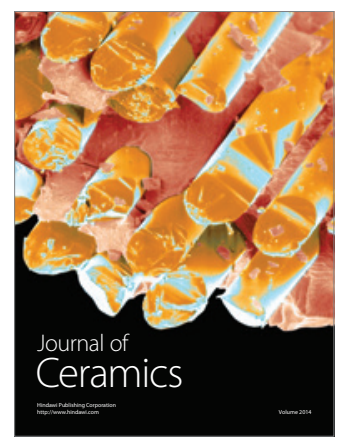

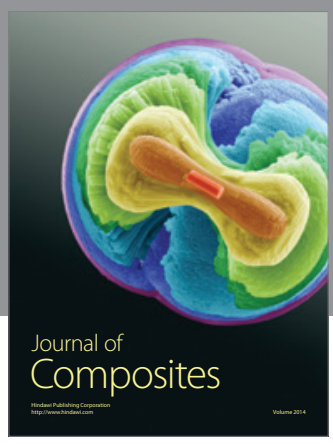
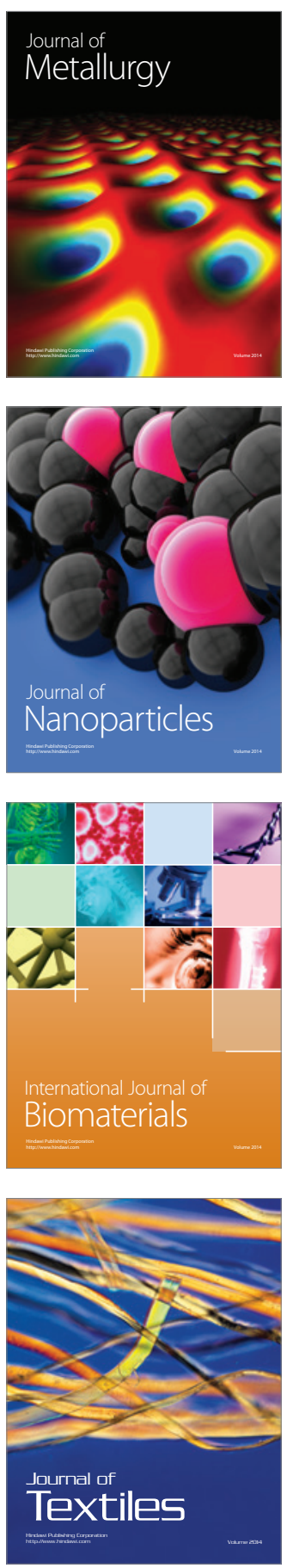